\title{
FREQUENCY DEPENDENT AMPLIFICATION OF WEAK GROUND MOTIONS IN PORIRUA AND LOWER HUTT, NEW ZEALAND
}

\author{
J. John Taber and Euan G. C. Smith ${ }^{2}$
}

\begin{abstract}
The relative ground response due to microearthquakes has been examined at a total of 36 sites in the Porirua and Lower Hutt regions of New Zealand, as part of a multi-disciplinary microzoning project conducted with the Wellington Regional Council. The sites were studied in two separate experiments and were chosen to sample a variety of soil typess and depths ranging from strong rock to thick sections of alluvial gravels and sands to soft water-saturated fine-grained deposits. The amplitude response of each site relative to a bedrock reference site has been determined as a function of frequency. Fourier spectral ratios (Fsr) were calculated for each earthquake and then between three and twenty-six earthquakes were averaged together at each of the sites. Spectral ratios of individual earthquakes varied significantly from the average spectral ratio.

In the Hutt Valley there is a gradual down-valley increase in shaking in a similar pattern to the down-valley increase of the depth to bedrock and thickness of near-surface soft sediment. The response at the upper-most valley sites, underlain by less than $50 \mathrm{~m}$ of alluvial gravel and silty sand, is similar to the response at the rock sites on the side of the valley (Fsr $=2.4$ ) while the Fourier spectral ratios reach 14 at the lower-most valley sites, which are underlain by greater than $20 \mathrm{~m}$ of soft sediment. The highest amplifications were recorded at two sites on soft flexible sediments ( 10 to $35 \mathrm{~m}$ thick) in an enclosed valley (Fsi $=16$ to 18 ) and a site on an apparently drained and filled swamp (Fsr $=15$ ). A spectral ratio of 18 corresponds to an increase in peak ground velocity by a factor of 5 .
\end{abstract}

The amplification at most Lower Hutt sites occurred over a broad frequency band from $0.5 \mathrm{~Hz}$ to up to $5 \mathrm{~Hz}$, with the high frequency limit of the band decreasing as the spectral ratio in the band increased. Two of the flexible sediment sites exhibited a very narrow frequency response with a peak in the $1-2 \mathrm{~Hz}$ range, similar to three flexible sediment sites in the Porirua basin where the amplification was in the 1-3 Hz frequency band. These flexible sediment sites had Fourier spectral ratios of up to 18 relative to a hard rock site. Three other Porirua sites had spectral ratios greater than 5 at some frequency. Two of these sites were on fan alluvium and fine grained sediment, while the third was on siltly sand on a topographic ridge. The remaining five sites were on weathered gravels and showed little amplification.

\section{INTRODUCTION}

Significant earthquake damage has occurred in San Francisco in 1989 and Mexico City in 1985 because of ground motion amplification at flexible sediment sites $^{1}$. Flexible sediment will be used to describe low velocity sediments capable of amplifying seismic waves. Such material is typically soft fine-grained sand, silts, or clays. Local geographic variations in ground motion have been observed over the entire range of earthquake shaking from microearthquakes [9] to earthquakes causing significant damage [3]. In regions where damaging earthquakes are expected, but infrequent, the ground response due to microearthquakes has been successfully used to identify areas of greater shaking hazard[2]. The frequency responses of a number of sites are usually compared to a nearby bedrock reference site, using the spectral ratio technique first introduced by Borcherdt [1].

\footnotetext{
${ }^{1}$ Institute of Geophysics, Victoria University of Wellington.

${ }^{2}$ Institute of Geological and Nuclear Sciences Fellow.
}

This paper describes such a microearthquake survey. The survey is one aspect of a multi-discipline microzoning project conducted for the Porirua and Hutt Valley regions in 1990-1991 (see [16] for a description of the overall project). The goal of the project is to provide a coherent picture of the ground shaking hazard facing the region. In this survey, microearthquakes have been recorded simultaneously at a variety of sites ranging from rock to soft fine-grained sediments, to measure the relative levels of shaking throughout the region. The ground motion at each site relative to a bedrock reference site is presented as a function of frequency (a spectral ratio). The average response of each site is determined by combining the spectral ratios from a number of different earthquakes. The average ratios could be used to calculate response spectra to show building response, but we have not done that here (see [10]). Directional effects were examined only briefly because the goal of the regional assessment of ground shaking hazard was to find the average response of each site. 


\section{DATA COLLECTION}

Three-component digital seismographs were installed at a total of 36 sites in the two study areas. Twelve seismographs were installed in the Porina region for a five week period during May and June, 1990 (Fig. 1 and Table 1) while 24 instruments were placed in the Hutt Valley region between November, 1990 and February, 1991 (Fig. 2 and Table 1). In Lower Hutt, the instruments were deployed primarily in two installments, with up to 18 seismographs operating at any one time. The $1 \mathrm{~Hz}$ natural period seismometers (Kinemetrics L4 3D) were operated with DSIR portable seismographs at a sampling rate of $100 \mathrm{~Hz}$ (see [5] for a description of the EARSS seismograph). The sites were chosen to sample the full range of soil types and depths in the region, from bedrock to thick flexible sediments. The seismometers were buried just beneath the surface in soil in the backyards of private homes or placed on existing concrete slabs at private or secure public locations.
In Lower Hutt, the sites extended $10 \mathrm{~km}$ up the valley from the Petone foreshore, with two additional sites in Wainuiomata (Fig.2) Six seismographs were placed next to existing or prior DSIR strong motion recorder sites so that a comparison could be made between strong and weak motion data (Table 2). Five sites were located on the sides of the valley on firm soil or bedrock. One of these, L14, was chosen as the reference site for the experiment.

In Porirua (Fig. 1), the reference site, PB8, was installed in very firm soil, adjacent to a rock outcrop. Sites PB4 and PB5 were chosen to be on thick (c. $10-15 \mathrm{~m}$ ) flexible sediment on the margin of Porirua Harbour. These flexible sediments had shear wave velocities as low as $110 \mathrm{~m} / \mathrm{s}$ [13]. Although site PB6 was located just outside the mapped flexible sediments, in the following analysis it will be discussed with PB4 and PB5 because it exhibited a similar response. These three sites will

Porirua Array

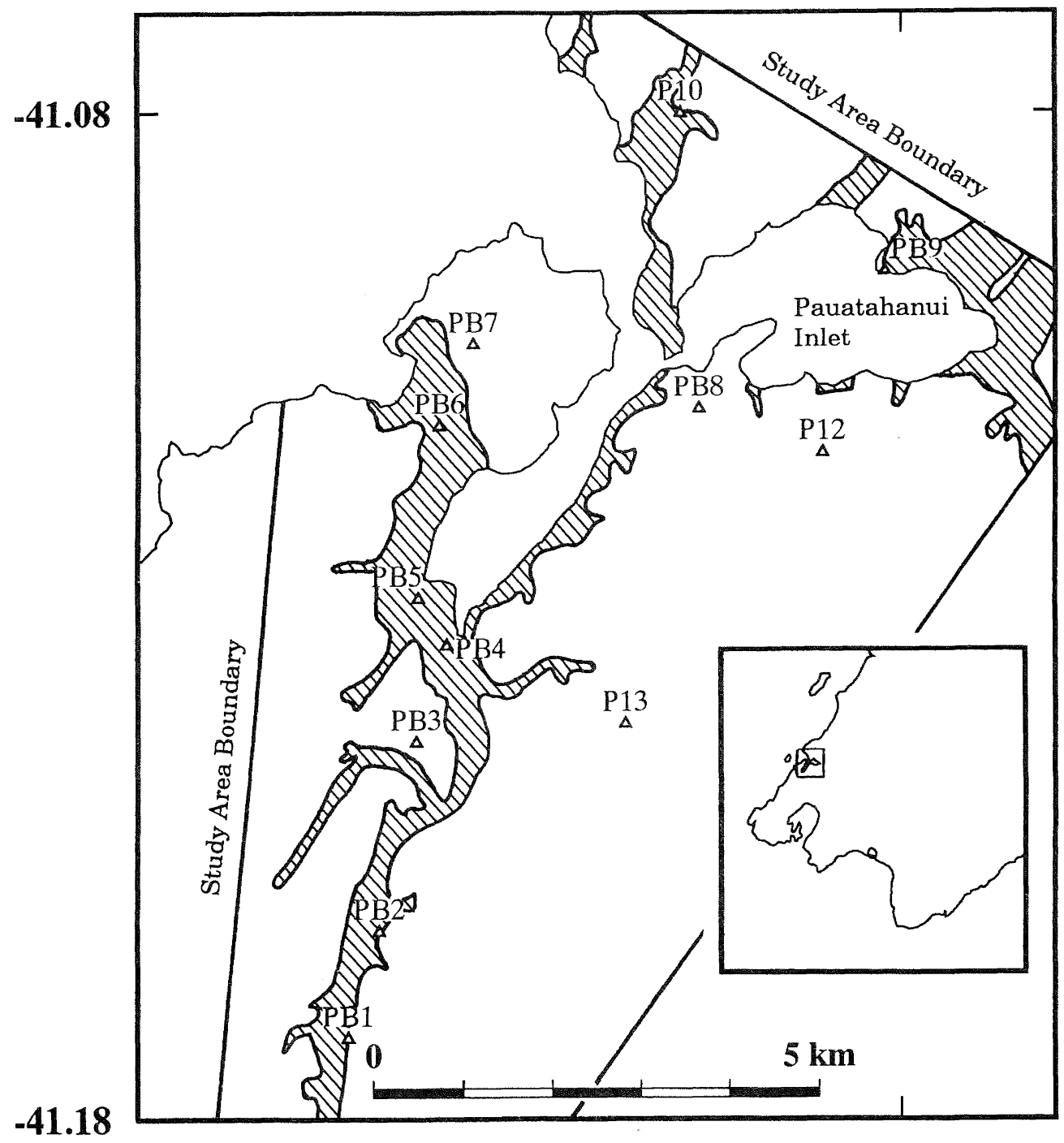

174.80

174.90

Figure 1. Station location map for the Porirua survey. Boxed area in inset shows Porirua region. Station PB8 is the reference site. PB4, PB5, and PB6 are the basin sites. Cross-hatched area is underlain by Quaternary-aged sediment. 
Table 1.

Station Locations - Porirua Array

\begin{tabular}{llcccc} 
Station & \multicolumn{1}{c}{ Address } & Latitude & Longitude & \multicolumn{2}{c}{ NZMG(EN) } \\
PB1 & 15 Duncan St., Tawa & -41.1722 & 174.8274 & 2663330 & 6002420 \\
PB2 & 3 Kowhai St., Linden & -41.1616 & 174.8314 & 2663690 & 6003590 \\
PB3 & Viard College, Porirua & -41.1427 & 174.8362 & 2664140 & 6005680 \\
PB4 & HVEB, Parumoana St., Porirua & -41.1332 & 174.8402 & 2664500 & 6006730 \\
PB5 & Tutu Rd., Porirua & -41.1286 & 174.8365 & 2664200 & 6007250 \\
PB6 & 84 Min St., Titahi Bay & -41.1115 & 174.8393 & 2664470 & 6009140 \\
PB7 & 10 Paunui St., Titahi Bay & -41.1033 & 174.8437 & 2664860 & 6010040 \\
PB8 & 56 Kahu Rd., Paremata & -41.1098 & 174.8736 & 2667350 & 6009270 \\
PB9 & Plimmerton-Pauatahanui Rd. & -41.0961 & 174.8979 & 2669430 & 6010740 \\
P10 & Ulric St., Plimmerton & -41.0801 & 174.8712 & 2667220 & 6012570 \\
P12 & 14 Companion Way & -41.1142 & 174.8898 & 2668700 & 6008750 \\
P13 & 23 Worchester St., Porirua East & -41.1409 & 174.8638 & 2666460 & 6005830
\end{tabular}

\section{Station Locations - Lower Hutt Array}

\begin{tabular}{llcccc} 
Station & \multicolumn{1}{c}{ Address } & Latitude & Longitude & \multicolumn{2}{c}{ NZMG(EN) } \\
L01 & DSIR Land Resources, Taita & -41.1793 & 174.9671 & 2675030 & 6001380 \\
L02 & 20A Avalon Cres., Avalon & -41.1930 & 174.9423 & 2672920 & 5999900 \\
L03 & 21 Belmont Tce, Belmont & -41.1925 & 174.9252 & 2671490 & 5999990 \\
L04 & 31 Ropata Cres., LH & -41.2040 & 174.9162 & 2670700 & 5998730 \\
L05 & DSIR, Knights Rd, LH & -41.2123 & 174.9042 & 2669680 & 5997830 \\
L06 & 46 Tama St., LH & -41.2173 & 174.8953 & 2668920 & 5997290 \\
L07 & 36 Titiro Rd., Korokoro & -41.2120 & 174.8643 & 2666330 & 5997940 \\
L08 & Singers Rd., Korokoro & -41.2190 & 174.8673 & 2666570 & 5997150 \\
L09 & IBM, The Esplanade, Petone & -41.2277 & 174.8710 & 2666860 & 5996180 \\
L10 & Petone Service Ctr., 7 Britannia St. & -41.2260 & 174.8788 & 2667510 & 5996360 \\
L11 & 72 Heretaunga St., Petone & -41.2303 & 174.8918 & 2668590 & 5995860 \\
L12 & Elizabeth St. Pumping Station & -41.2322 & 174.9087 & 2670010 & 5995610 \\
L13 & DSIR, Physical Sciences & -41.2360 & 174.9175 & 2670730 & 5995180 \\
L14 & DSIR, Inst. Nuclear Sci. & -41.2350 & 174.9205 & 2670990 & 5995280 \\
L15 & Shell Oil, Seaview Rd. & -41.2458 & 174.9075 & 2669870 & 5994110 \\
L16 & 56 Meremere St., Winui. & -41.2482 & 174.9368 & 2672320 & 5993790 \\
L17 & 5 Miles Cres., Winui. & -41.2563 & 174.9480 & 2673240 & 5992870 \\
L18 & St. Bernadettes, Naenae Rd. & -41.2030 & 174.9537 & 2673850 & 5998770 \\
L19 & Naenae reservoir & -41.2095 & 174.9402 & 2672700 & 5998080 \\
L20 & 4A Trinity Ave., LH & -41.2055 & 174.9303 & 2671880 & 5998540 \\
L21 & 60 Witako Ave., LH & -41.2098 & 174.9243 & 2671370 & 5998070 \\
L22 & 1 Malone St., LH & -41.2203 & 174.9217 & 2671120 & 5996910 \\
L23 & 13 Maire St., LH & -41.2207 & 174.9097 & 2670120 & 5996890 \\
L24 & 8 Victoria St., Petone & -41.2280 & 174.8727 & 2667020 & 5996160
\end{tabular}

Table 2. Co-located ground motion sites in Lower Hutt. See [10] for description of accelerograph records at these sites.

\section{Weak Motion Strong Motion}

$\begin{array}{ll}\text { L05 } & \text { NZGS } \\ \text { L09 } & \text { GMT } \\ \text { L12 } & \text { ELS } \\ \text { L13 } & \text { PEL } \\ \text { L14 } & \text { INS } \\ \text { L19 } & \text { NAE }\end{array}$




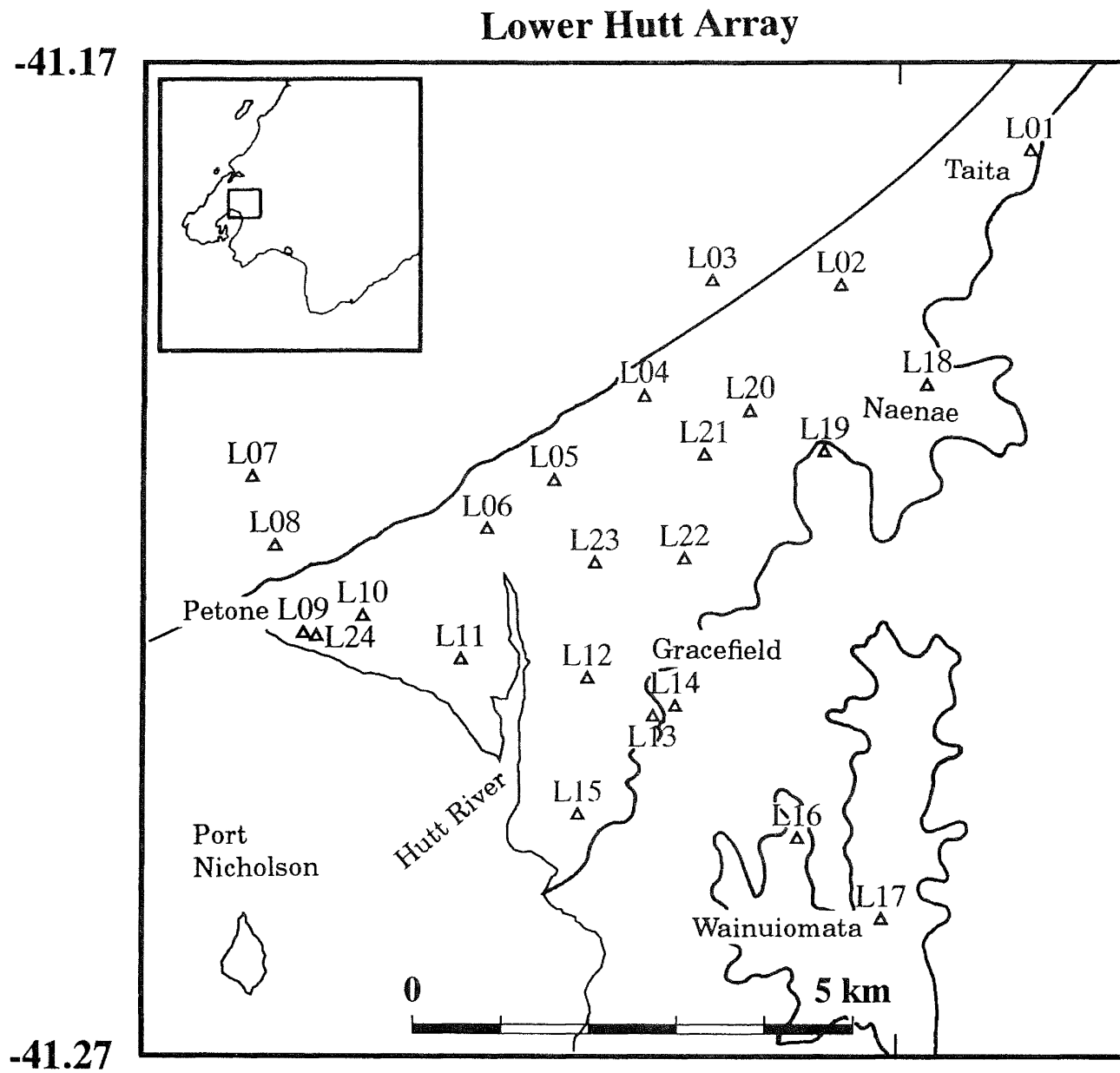

174.85

174.95

Figure 2. Station location map for the Lower Hutt survey. Boxed area in inset shows Lower Hutt region. Station L14 is the reference site. The thick lines mark the contact between bedrock and Quaternary-aged sediment.

be referred to as the Porirua basin sites. The remaining sites spanned a $10 \mathrm{~km}$ by $5 \mathrm{~km}$ region.

The earthquakes chosen for the analysis of the two regions are shown separately in Figs. 3 and 4 and listed in Table 3. There were 26 earthquakes used in the Porirua study and 33 earthquakes used in the Lower Hutt study. The events ranged in magnitude from 2.5 to 5.8 and were between 5 and $400 \mathrm{~km}$ from centre of each array. Very few of the events were large enough to be felt in the study regions. Most of the events were in the depth range of 5-60 km but a few deep shocks (depths to $230 \mathrm{~km}$ ) were also included in the analysis.

\section{DATA ANALYSIS}

The results will be presented as velocity seismograms from each site, as averaged ratios of Fourier spectra of the seismograms, and as particle motion plots. Fig. 5 is an example of a plot of the raw seismograms versus distance for Porirua and shows many of the features of the later plots. This plot shows the north-south (horizontal) component for an earthquake at $70 \mathrm{~km}$ distance and is essentially a measure of ground velocity. The scaling is the same for all the traces and each trace is labeled with its station name. The smallest $S$ wave amplitude is visible on PB8, the very stiff soil reference site. The highest amplitudes occur at the flexible sediment sites PB4, PB5 and PB6. Note the low frequency response at these sites and the length of time that the high amplitudes continue. The highest amplitude at the flexible sediment sites does not occur until several seconds after the initial arrival of the $S$ wave. Earthquakes from other directions and distances show nearly the same effect.

Fig. 6 is a plot of the seismograms recorded in the Hutt Valley for an earthquake at $160 \mathrm{~km}$ distance for a line of sites trending roughly across the valley. The smallest amplitude response is visible at sites L07 and L08 located on rock on the west side of the valley and $\mathrm{L} 14$, the reference site on the east side of the valley. The initial amplitude of the shaking at the sites in the valley (L05, L06, L10, L12, and L15) is similar or only slightly higher than at the rock sites but the shaking continues much longer at the valley sites. The two sites in Wainuiomata (L16 and L17) show much greater amplification of the shaking as well as increased duration. 


\section{Porirua Sources}

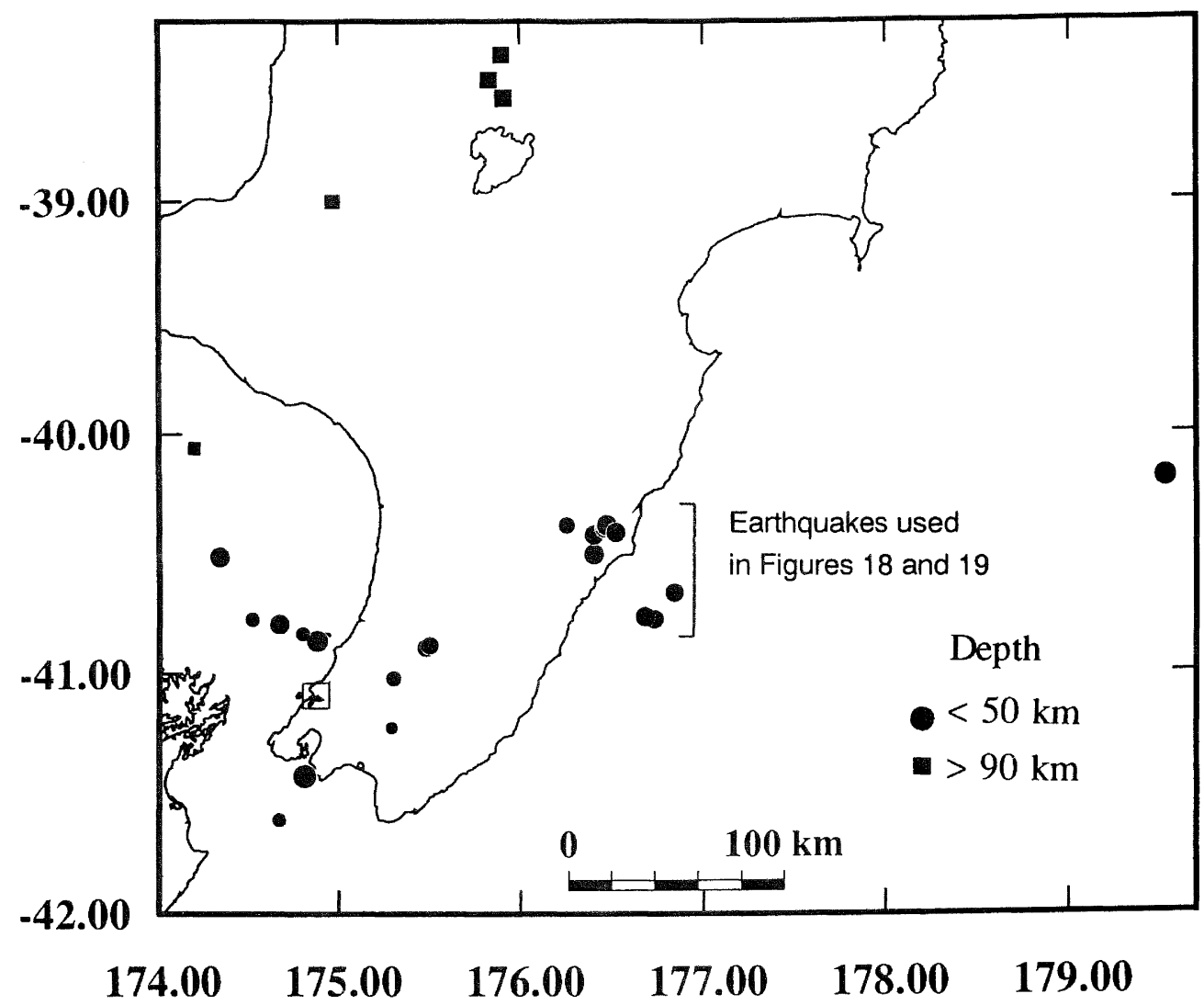

Figure 3. Locations of earthquakes used in the Porirua survey. Events are scaled by magnitude and range from 2.6 to 4.8 . Filled squares are events deeper than $90 \mathrm{~km}$.

Table 3. Earthquake locations (from DSIR Seismological Observatory)

Porirua Array

$\begin{array}{llcccccrc}\text { Year } & \text { Mon } & \text { Day } & \text { Hrmn } & \text { Sec } & \text { Lat } & \text { Lon } & \text { Depth } & \text { Mag } \\ 1990 & \text { JUN } & 02 & 0728 & 30.74 & 38.46 \mathrm{~S} & 175.83 \mathrm{E} & 180.8 & 4.6 \\ 1990 & \text { JUN } & 02 & 2244 & 20.25 & 40.50 \mathrm{~S} & 176.40 \mathrm{E} & 29.4 & 3.8 \\ 1990 & \text { JUN } & 03 & 1219 & 26.85 & 40.06 \mathrm{~S} & 174.20 \mathrm{E} & 96.7 & 3.4 \\ 1990 & \text { JUN } & 03 & 2151 & 02.60 & 41.61 \mathrm{~S} & 174.67 \mathrm{E} & 28.9 & 2.6 \\ 1990 & \text { JUN } & 04 & 0504 & 11.36 & 40.42 \mathrm{~S} & 176.40 \mathrm{E} & 32.1 & 3.6 \\ 1990 & \text { JUN } & 04 & 1244 & 20.16 & 40.86 \mathrm{~S} & 174.88 \mathrm{E} & 34.8 & 4.1 \\ 1990 & \text { JUN } & 05 & 1433 & 02.02 & 40.38 \mathrm{~S} & 176.25 \mathrm{E} & 21.1 & 3.1 \\ 1990 & \text { JUN } & 05 & 2329 & 36.54 & 39.00 \mathrm{~S} & 174.97 \mathrm{E} & 230.6 & 4.1 \\ 1990 & \text { JUN } & 09 & 1818 & 06.59 & 40.39 \mathrm{~S} & 176.46 \mathrm{E} & 32.6 & 3.7 \\ 1990 & \text { JUN } & 10 & 1227 & 20.89 & 38.35 \mathrm{~S} & 175.90 \mathrm{E} & 200.7 & 4.5 \\ 1990 & \text { JUN } & 11 & 1058 & 27.76 & 40.78 \mathrm{~S} & 176.74 \mathrm{E} & 25.3 & 3.5 \\ 1990 & \text { JUN } & 11 & 1337 & 20.21 & 40.19 \mathrm{~S} & 179.53 \mathrm{E} & 28.1 & 4.3 \\ 1990 & \text { JUN } & 12 & 1221 & 10.12 & 40.77 \mathrm{~S} & 176.68 \mathrm{E} & 26.2 & 3.7 \\ 1990 & \text { JUN } & 13 & 1251 & 39.20 & 40.78 \mathrm{~S} & 174.52 \mathrm{E} & 48.4 & 2.7 \\ 1990 & \text { JUN } & 14 & 1440 & 03.00 & 38.55 \mathrm{~S} & 175.91 \mathrm{E} & 134.2 & 4.8 \\ 1990 & \text { JUN } & 15 & 1501 & 00.32 & 40.79 \mathrm{~S} & 174.67 \mathrm{E} & 44.4 & 3.7 \\ 1990 & \text { JUN } & 16 & 1219 & 59.33 & 40.89 \mathrm{~S} & 175.48 \mathrm{E} & 22.3 & 3.4 \\ 1990 & \text { JUN } & 16 & 1436 & 54.22 & 40.88 \mathrm{~S} & 175.50 \mathrm{E} & 26.6 & 3.3 \\ 1990 & \text { JUN } & 16 & 1639 & 51.51 & 40.66 \mathrm{~S} & 176.84 \mathrm{E} & 32.4 & 3.5 \\ 1990 & \text { JUN } & 17 & 1023 & 32.36 & 40.38 \mathrm{~S} & 176.48 \mathrm{E} & 30.8 & 3.8 \\ 1990 & \text { JUN } & 17 & 1452 & 28.75 & 40.84 \mathrm{~S} & 174.80 \mathrm{E} & 5.0 & 2.7 \\ 1990 & \text { JUN } & 17 & 1631 & 28.84 & 40.41 \mathrm{~S} & 176.52 \mathrm{E} & 32.6 & 3.6 \\ 1990 & \text { JUN } & 20 & 1509 & 35.39 & 41.23 \mathrm{~S} & 175.29 \mathrm{E} & 25.4 & 2.3 \\ 1990 & \text { JUN } & 24 & 0245 & 50.98 & 41.03 \mathrm{~S} & 175.31 \mathrm{E} & 10.2 & 2.9 \\ 1990 & \text { JUN } & 24 & 0758 & 58.71 & 40.51 \mathrm{~S} & 174.35 \mathrm{E} & 54.9 & 3.7 \\ 1990 & \text { JUN } & 28 & 0247 & 56.76 & 41.44 \mathrm{~S} & 174.81 \mathrm{E} & 30.6 & 4.4\end{array}$


Lower Hutt Array

\begin{tabular}{|c|c|c|c|c|c|c|c|c|}
\hline Year & Mon & Day & Hrmn & Sec & Lat & Lon & Depth & Mas \\
\hline 1990 & NOV & 27 & 1529 & 5.18 & $40.41 \mathrm{~S}$ & $174.46 \mathrm{E}$ & 7.0 & \\
\hline 1990 & NOV & 29 & 1454 & 30.62 & $39.80 \mathrm{~S}$ & $174.55 \mathrm{E}$ & 104.4 & \\
\hline 990 & NOV & 29 & 2305 & 0.60 & $40.69 \mathrm{~S}$ & $174.66 \mathrm{E}$ & 58.9 & \\
\hline 990 & NOV & 29 & 2321 & 7.96 & $40.68 \mathrm{~S}$ & $174.63 \mathrm{E}$ & 62.6 & \\
\hline 1990 & NOV & 30 & 1738 & 37.08 & $40.73 \mathrm{~S}$ & $174.95 \mathrm{E}$ & 16.1 & \\
\hline 990 & DEC & 9 & 0742 & 13.34 & $40.64 \mathrm{~S}$ & $175.39 \mathrm{E}$ & 40.9 & \\
\hline 990 & DEC & 12 & 0702 & 26.81 & $41.62 \mathrm{~S}$ & $175.37 \mathrm{E}$ & 25.0 & \\
\hline 990 & DEC & 13 & 1242 & 7.83 & $41.27 \mathrm{~S}$ & $174.84 \mathrm{E}$ & 26.8 & \\
\hline 990 & DEC & 13 & 1244 & 5.00 & $41.27 \mathrm{~S}$ & $174.84 \mathrm{E}$ & 28.8 & \\
\hline 990 & DEC & 13 & 1258 & 30.41 & $41.27 \mathrm{~S}$ & $174.84 \mathrm{E}$ & 27.3 & \\
\hline 990 & DEC & 16 & 1454 & 8.78 & $41.14 \mathrm{~S}$ & $175.16 \mathrm{E}$ & 33.0 & \\
\hline 1990 & DEC & 16 & 1608 & 32.24 & 41. & $64 \mathrm{E}$ & 58.9 & 3 \\
\hline 990 & DEC & 18 & 1522 & 14.88 & 40.1 & $174.90 \mathrm{E}$ & 12.0 & \\
\hline 990 & DEC & 19 & 1100 & 5.50 & $40.44 \mathrm{~S}$ & $176.52 \mathrm{E}$ & 40.4 & 3 \\
\hline 990 & DEC & 20 & 1558 & 57.86 & $40.95 \mathrm{~S}$ & $174.65 \mathrm{E}$ & 65.6 & \\
\hline 1990 & DEC & 23 & 2008 & 16.30 & $41.02 \mathrm{~S}$ & $174.59 \mathrm{E}$ & 42.0 & \\
\hline 1990 & DEC & 26 & 1120 & 8.66 & $39.05 \mathrm{~S}$ & $175.26 \mathrm{E}$ & 139.8 & 4. \\
\hline 1990 & $\mathrm{DEC}$ & 29 & 1049 & 51.16 & $41.31 \mathrm{~S}$ & $174.11 \mathrm{E}$ & 48.6 & \\
\hline 991 & JAN & 8 & 1400 & 38.23 & $40.88 \mathrm{~S}$ & $175.65 \mathrm{E}$ & 26.5 & \\
\hline 1991 & JAN & 9 & 1334 & 30.11 & $41.44 \mathrm{~S}$ & $174.82 \mathrm{E}$ & 29.4 & \\
\hline 1991 & JAN & 9 & 1550 & 14.91 & $41.06 \mathrm{~S}$ & $174.73 \mathrm{E}$ & 59.9 & \\
\hline 1991 & JAN & 11 & 1645 & 3.28 & $40.77 \mathrm{~S}$ & $176.32 \mathrm{E}$ & 25.2 & \\
\hline 991 & JAN & 15 & 1045 & 31.46 & 40.4 & $174.47 \mathrm{E}$ & 13.1 & \\
\hline 1991 & JAN & 17 & 1712 & 54.52 & & $32 \mathrm{E}$ & 193.2 & \\
\hline 1991 & JAN & 18 & 54 & 46 & & $45 \mathrm{E}$ & 200.1 & \\
\hline 199 & JAN & 22 & 1443 & 9.72 & & $175.40 \mathrm{E}$ & 23.6 & 3 \\
\hline 1991 & JAN & 23 & 1233 & 41.10 & $41.14 \mathrm{~S}$ & $175.16 \mathrm{E}$ & 25.2 & 2 \\
\hline 99 & JAN & 24 & 1714 & 53.04 & $40.73 \mathrm{~S}$ & $175.38 \mathrm{E}$ & 33.8 & \\
\hline 1991 & JAN & 26 & 1133 & 18.11 & $41.59 \mathrm{~S}$ & $174.48 \mathrm{E}$ & 10.9 & \\
\hline 1991 & JAN & 28 & 1258 & 47.50 & $41.89 \mathrm{~S}$ & $171.61 \mathrm{E}$ & 8.3 & \\
\hline 1991 & JAN & 28 & 1800 & 54.52 & $41.90 \mathrm{~S}$ & $171.73 \mathrm{E}$ & 17.3 & \\
\hline 1991 & FEB & 1 & 1742 & 14.24 & $41.64 \mathrm{~S}$ & $175.49 \mathrm{E}$ & 23.8 & \\
\hline 1501 & FEB & 2 & 1506 & 1.43 & $40.43 \mathrm{~S}$ & $176.40 \mathrm{E}$ & 34.2 & \\
\hline
\end{tabular}

Lower Hutt Sources

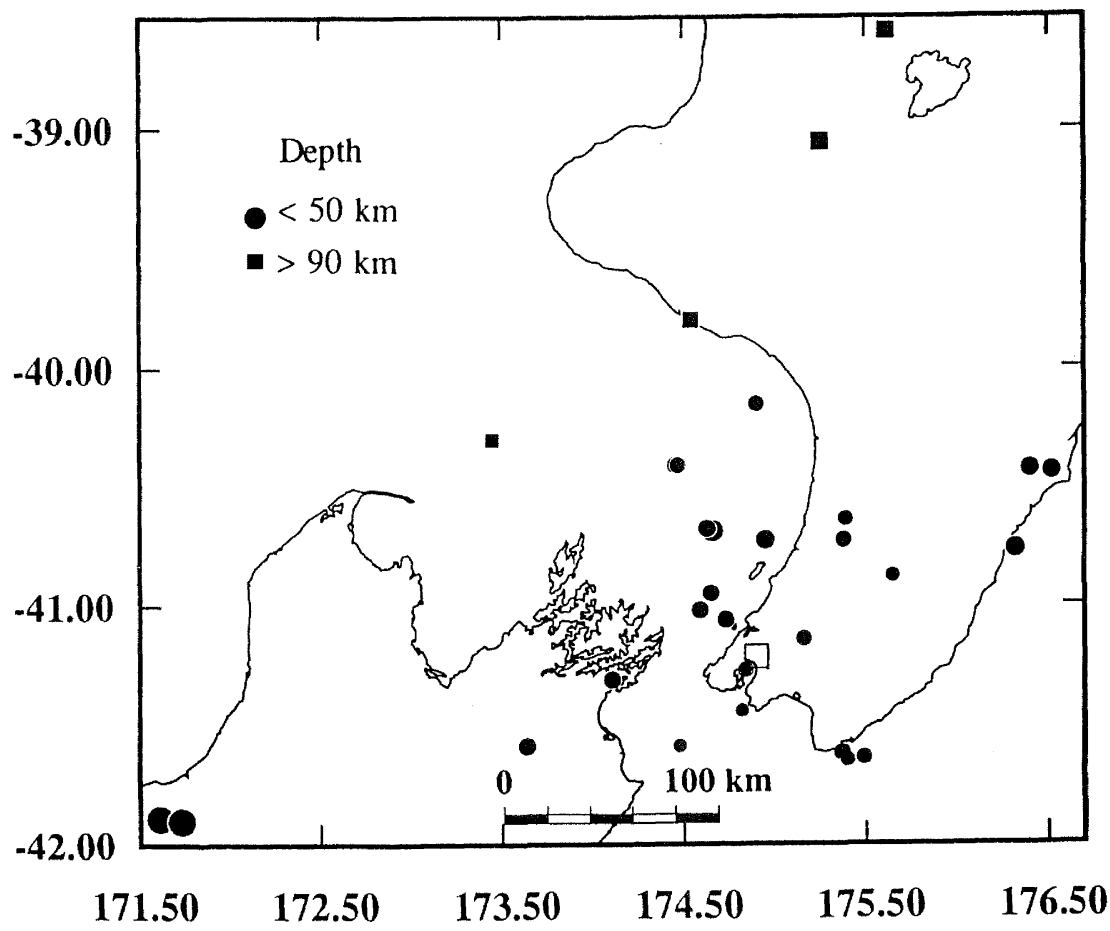

Figure 4. Locations of earthquakes used in the Lower Hutt survey. Events are scaled by magnitude and range from 2.5 to 5.8. Filled squares are events deeper than $90 \mathrm{~km}$. 


\section{Porirua}

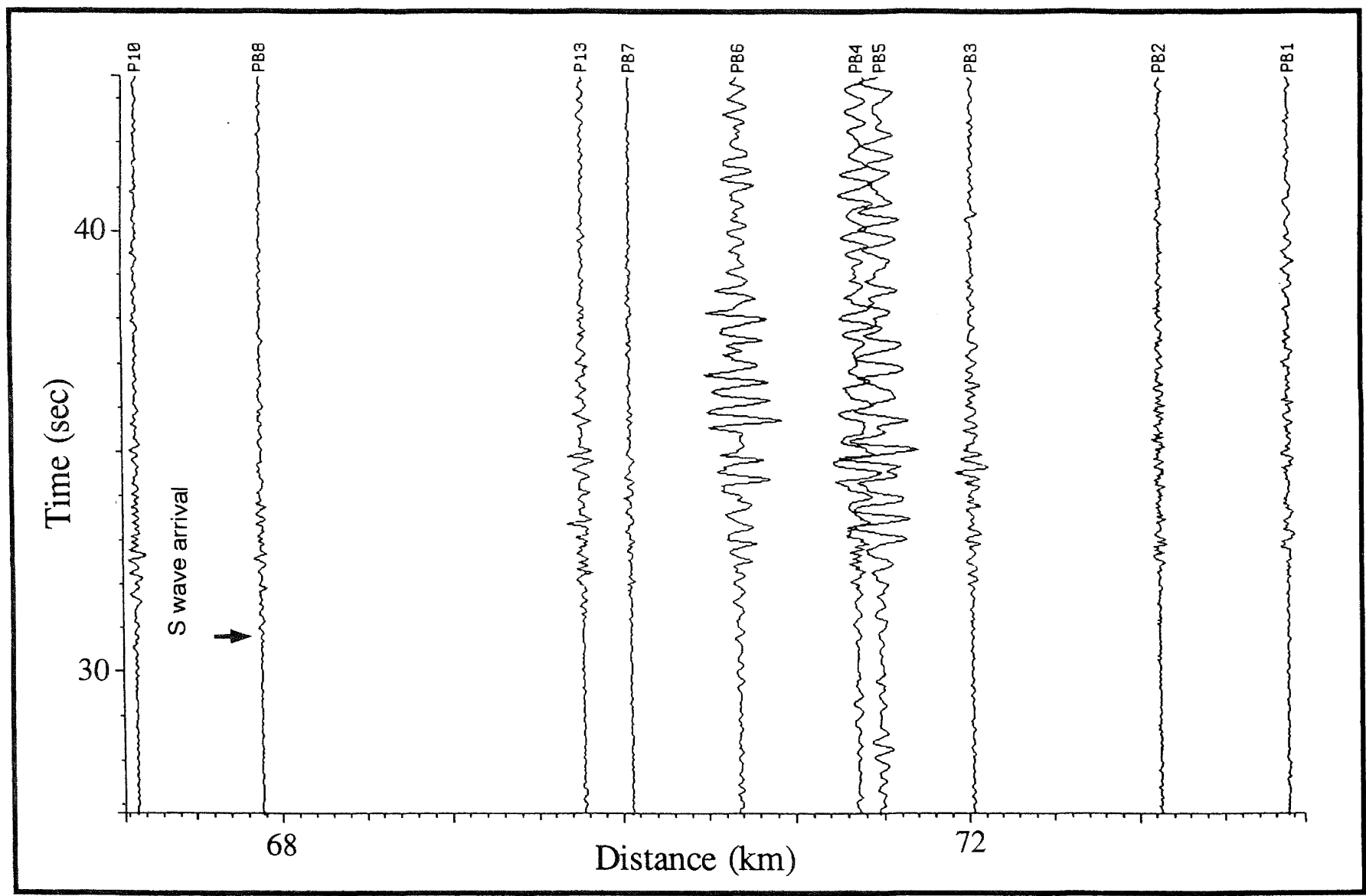

North-South Component

Date: 09/06/90 18:18

Figure 5. Seismograms displayed as a function of distance for one earthquake. The N-S horizontal component is shown for each station. Note the high amplitude and low frequency character of the basin sites (PB4, PB5 and PB6) relative to rock sites $\mathrm{PB} 7$ and $\mathrm{PB} 8$. The maximum velocity at site PB6 is $0.15 \mathrm{~mm} / \mathrm{s}$.

Fig. 7 shows the variation of shaking from the harbour to the northern extent of the array for an earthquake $290 \mathrm{~km} \mathrm{WSW}$ from the sites. Other than the rock sites L08 and L14, there is a gradual decrease in amplitude from site L24 on the Petone foreshore to site L20, $5 \mathrm{~km}$ up the valley. Site L19 is another rock site on the east side of the valley. Site L18, which exhibits the most amplification, is located on a pocket of flexible material (a drained swamp?) in Naenae [4].

\section{SPECTRAL RATIOS}

Fourier spectra were calculated to quantify the variation in amplification seen in Figs. 5-7. A ten second window starting 0.5 second before the $S$ wave arrival was selected for each recording. A Hanning taper was applied to $4 \%$ of each end of the data and then a Fourier amplitude spectrum was calculated. The spectra were smoothed with a $1 \mathrm{~Hz}$ triangular moving window. Spectral ratios were then calculated by dividing each of the spectra by the spectrum of the reference station for that event (either PB8 for Porirua or L14 for Lower Hutt). Since the seismograms are a measure of ground velocity, the spectra also refer to ground velocity. However the ratios are the same whether the initial spectra are calculated for velocity or acceleration. The upper frequency limit was chosen by examining signal to noise ratios for a number of stations. In the Porirua survey, the signal to noise ratio begins to drop below 4 for some stations near $12 \mathrm{~Hz}$. An example of the Fourier spectra and the resulting spectral ratios for a few stations for one earthquake is shown in Fig. 8. The N-S component is plotted in this and all remaining figures as the results for the E-W component are similar and the goal of this survey was to find the average response of each site. The directional effects which are evident for some stations will be the subject of a later study. The amplitude spectra have not been corrected for the frequency response of the seismometer, but the instrument responses are effectively removed by taking the ratios of the amplitude spectra. The use of ratios also reduces effects due to the earthquake source or variations in the path between the source and receiver [7]. 
90/11/29 14:54 North Component
L07
L08 L05
L06
L10
L12
L15 L13
L14
L16
L17

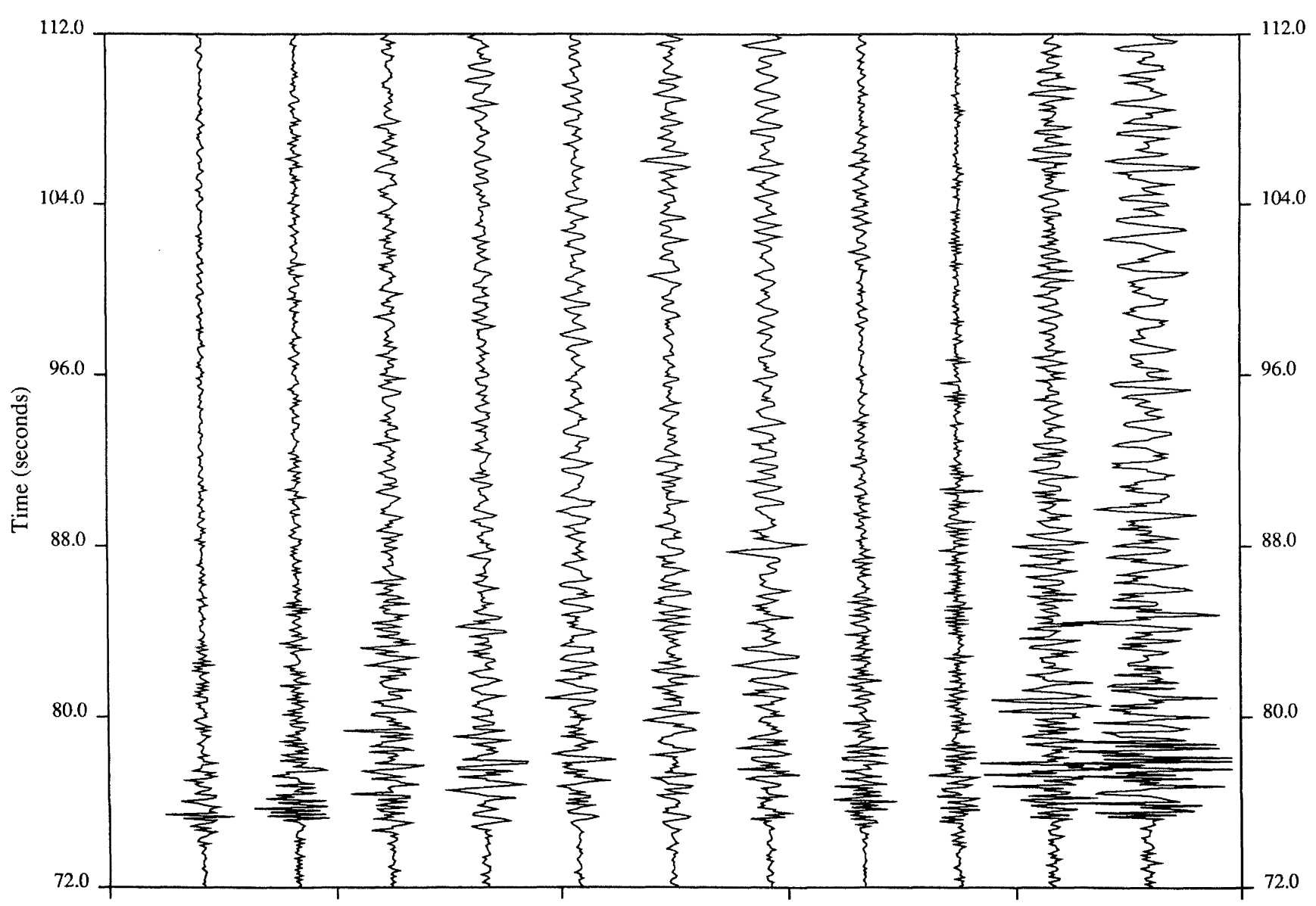

Figure 6. Seismograms displayed in roughly an east-west line across the Hutt Valley from L07 (a rock site) to Petone (L10) to Gracefield (L13 and L14) to Wainuiomata (L16 and L17, flexible sediment sites) for one earthquake. The $S$ wave as recorded on the N-S horizontal component is shown for each station. L14 is the reference site. The maximum velocity at site $\mathrm{L} 17$ is $0.35 \mathrm{~mm} / \mathrm{s}$. 
91/01/28 12:59 North Component

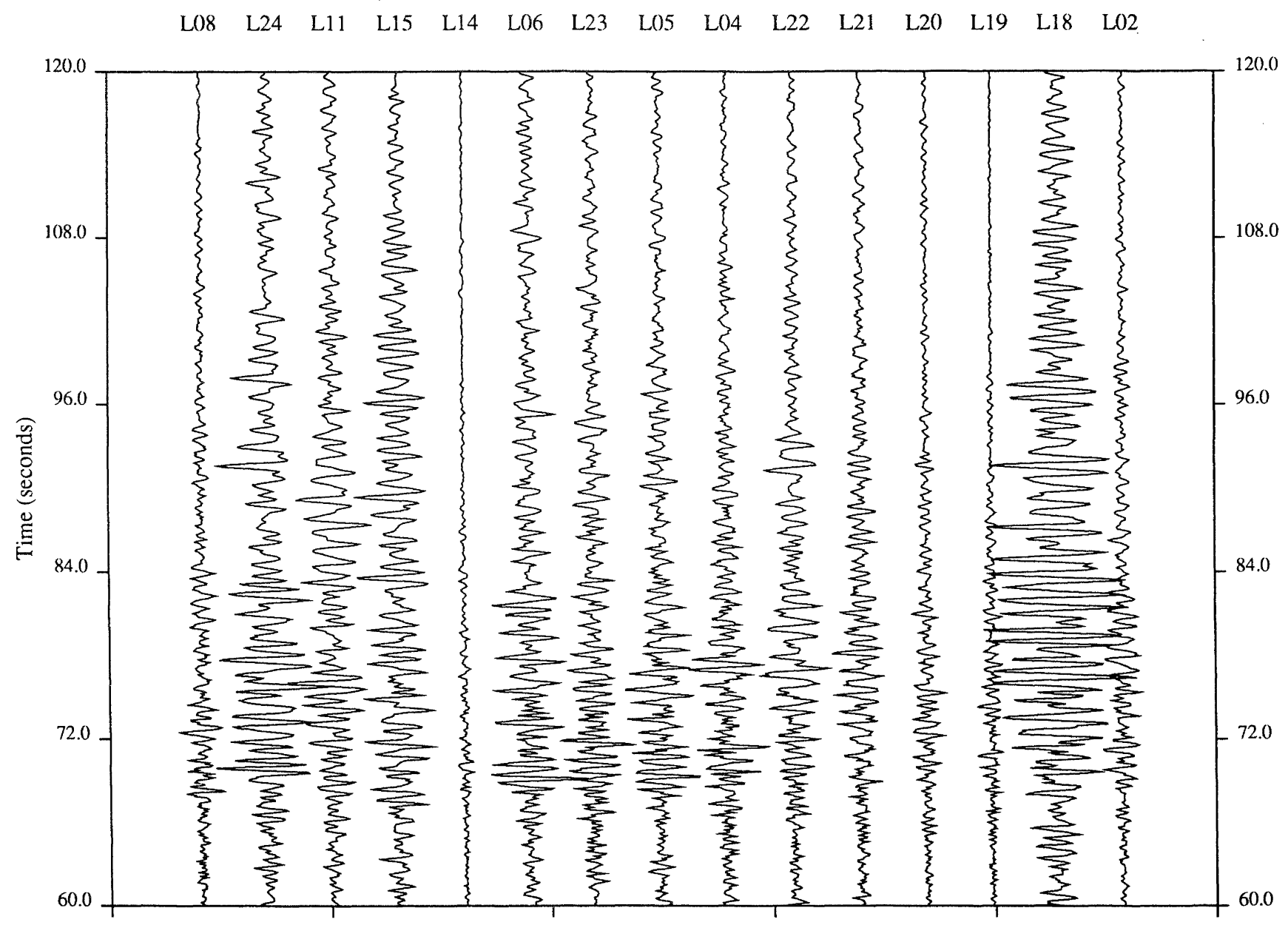

Figure 7. Seismograms displayed approximately along the length of the Hutt Valley. The firm, valley edge sites are L08, L14, and L19. There is a general decrease in amplitude when going up-valley from Petone (L24) to L02. Note the high amplitude at L18, which is located over a drained and filled swamp in Naenae. The maximum velocity at site $\mathrm{L} 18$ is $4.5 \mathrm{~mm} / \mathrm{s}$. 


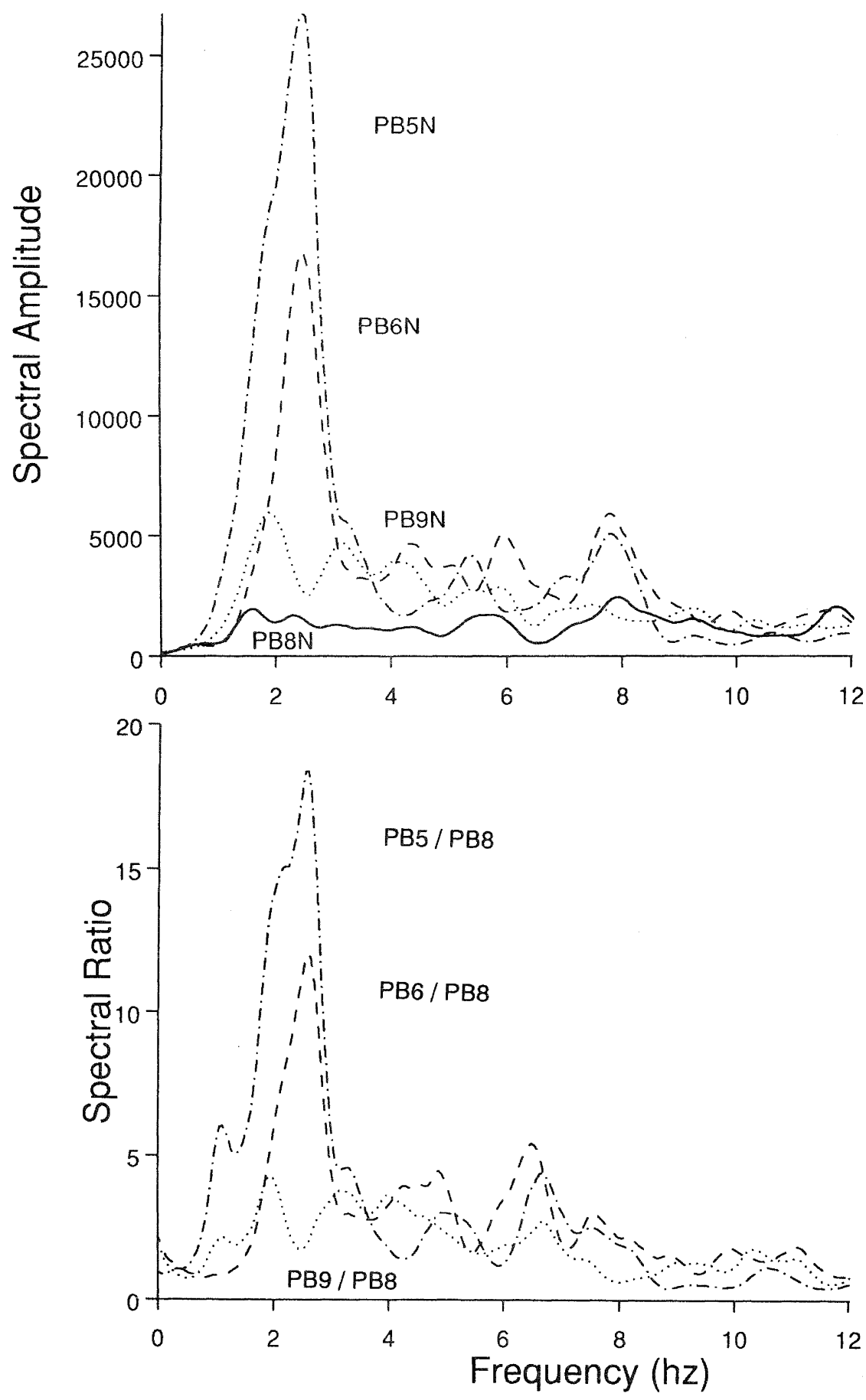

Figure 8. Top: Fourier spectral amplitude of the N-S component for 4 stations for an earthquake that occurred on $3 / 6 / 90$ at 12:19.

Bottom: Spectral ratios for the 3 stations shown above.

All stations are divided by PB8. 
There are limitations to the spectral ratio technique. The reference spectrum (PB8 in Fig. 8) is not as flat as predicted by simple source theory, perhaps due to interference between signals arriving via slightly different paths. These low points in the reference spectrum create possibly spurious high ratios where there was not a high signal in the original spectrum. For example, in Fig. 8 the low point in the PB8 spectrum at $6.5 \mathrm{~Hz}$ creates a peak in the spectral ratios for PB5 and PB6 at the same frequency. The additional scatter added by this problem can be reduced either by heavier smoothing of the original spectrum or by averaging ratios from many events at the same station. Since some useful frequency information may be lost by too much smoothing, we have chosen to average many events.

An example of the range of spectral ratios for two stations underlain by $10-35 \mathrm{~m}$ of flexible sediment (L16 and L17) is shown in Fig. 9. A maximum at $2 \mathrm{~Hz}$ is apparent for almost all events for $\mathrm{L} 16$ whereas there are multiple peaks for L17. In both cases there is a wide range of values for individual earthquakes about the mean (shown by the dark line). The narrow range of frequencies over which amplification occurs implies a resonance in the sediments. To a first approximation, the resonant frequency is a function of the thickness and velocity of the flexible sediments. The lower frequency peak near $1 \mathrm{~Hz}$ for L17 is in good agreement with the shear wave resonance predicted by Stephenson and Barker[13] based on the shear wave propagation time for the entire thickness of flexible material. At L17 the flexible sediment has a thickness of $30-35 \mathrm{~m}$ and a shear wave velocity of $90-150 \mathrm{~km} / \mathrm{s}$ [13]. There are two layers of flexible material at site L17 with different velocities [13], which may account for the multiple peaks in the frequency spectrum. Near site L16, which has a resonant peak near $2 \mathrm{~Hz}$, the flexible material extends only to a depth of $12 \mathrm{~m}$ [13].

The width and height of the resonance peak is dependent on the amount of smoothing applied to the raw spectra. If the smoothing is reduced by a factor of 4 (using a $0.25 \mathrm{~Hz}$ moving window instead of a $1 \mathrm{~Hz}$ window), the height of the peak doubles and the width is reduced by a factor of 2 . Further reduction in smoothing does not narrow the peak. For stations like L17 with multiple peaks, reducing the smoothing narrows the peaks for individual earthquakes but has little effect on the mean. The range of ratios shown for L16 and L17 is similar for each of the other stations in the two surveys. The spectral ratios for other selected stations are shown in the appendix. As seen in Table 4 , in all but a few cases the standard deviation for each station varies between about 0.3 and 0.6 of the value of the mean at that point. For example, one standard deviation at the peak of the L16 ratio (mean $=16.3$ ) is 10.0 . Thus there is a wide range of values about the mean, and an individual earthquake can produce a response significantly differently from the average. The number of events used for the mean varies from 3 for L09 to 26 for site L02. (Site L24 is not included in the table or the following mean spectral ratio plots because only two earthquakes were recorded there.)

Another way to look at the scatter of data about the mean is to divide the ratios at a given frequency by the mean at that frequency and then plot the range of normalised ratios. In Fig. 10 (top) the distribution of normalized ratios have been plotted for the four frequencies in Table 4 for station PB1 sited on alluvial gravel (spectral ratios plotted in Fig. A2). The plot shows a log-normal distribution of ratios, with the largest number of values just below the mean and occasional values exceeding the mean by as much as a factor of three. Fig. 10 (bottom) plots the distribution of normalized ratios for three stations at the same frequency. These are the three Porirua stations which show a resonant peak at 2-3 Hz. In this case the ratios appear to be normally distributed about the mean, though there are insufficient data to make a definite conclusion. A difference between the distributions in Fig. 10 top and bottom might imply a different underlying cause for the scatter of the amplitude ratios depending on whether or not the site exhibits a resonant behaviour.

Some of the scatter is due to variations in the azimuth and distance to the earthquake source but focal mechanism and depth is probably also important. In Porirua, the range of ratios at one station is slightly reduced when only aftershocks of one earthquake are considered, but other spatially related groups of earthquakes have spectral ratios which vary over the entire range of values. The amplification from individual events appears to be more dependent on the direction of the earthquake source in Lower Hutt than in Porirua.

Part of the scatter may also be due to the assumption that the north component on a flexible site correlates with the north component on the reference site. It has been shown [12] that the resonance direction at the flexible sediment site can be different than the direction of maximum motion at the rock reference site.

The mean ratios for all Porirua stations are plotted in Fig. 11 The most prominent feature is the very narrow peak at $\sim 2.5 \mathrm{~Hz}$ at the three basin sites. The slight difference in peak frequency between the 3 stations is probably not significant, considering the scatter in the ratio data. Two other stations also stand out above the general trend. There is a ratio of nearly 10 for station P12 at $5.5 \mathrm{~Hz}$. The standard deviation for P12 (ranging between 0.3 and 0.5 ) is about the same as for the other stations even though there are many fewer events $(5$, as opposed to 22 events for PB6). Station P12 is located on the flank of a bedrock ridge and is in the same area where there were high intensities from a felt earthquake in May, 1990 [6]. The amplification at site P12 could be due in part to topographic effects since amplifications of up to 8 have been recorded at hard-rock ridge-crest sites [15]. Site PB2, underlain by less than $3 \mathrm{~m}$ of soft sediment [13], had a maximum at the highest frequency $(10.5 \mathrm{~Hz})$. This may be a very localised effect because site PB1, only $1.2 \mathrm{~km}$ south, had no such maximum. The sediments in the stream bed a few hundred meters west of these two stations do thicken from 1 to $2.8 \mathrm{~m}$ between PB1 and PB2 [13], but otherwise there is little difference in the sites.

The scale has been increased in Fig. 12 to highlight the response of the remainder of the stations. The five sites with the highest ratios have been removed. PB9 stands out in this group with the same peak frequency as the basin sites, though with much lower amplification. The site is on the north side of the Pauatahanui Inlet and is underlain by firm materials (stiffer than sand) close to the flexible materials of the basin [13]. Stephenson and Barker [13] suggest that basin resonance effects may penetrate beyond the physical boundary of the basin. A similar effect may be occurring at site PB6, which is just outside the mapped flexible sediments, but exhibits strong resonant behaviour. 


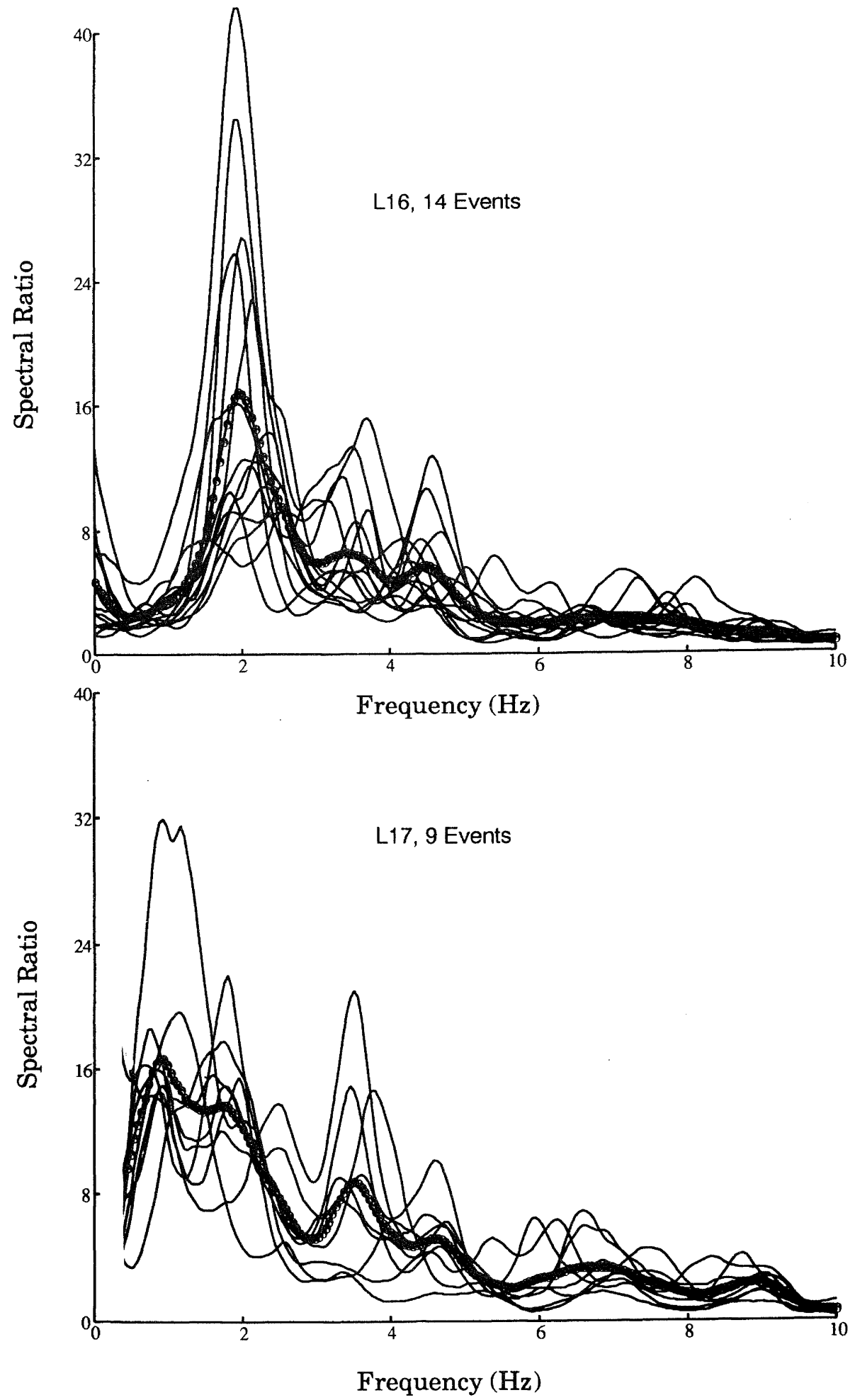

Figure 9. Top: Fourier spectral ratios (L16 divided by the reference site L14) of the N-S component for all events for one station. Dark line with circles is the mean of the spectral ratios.

Bottom: Spectral ratios for all events for site L17. 
Table 4. Amplification Ratio Means and Standard Deviations

Porirua Array

\begin{tabular}{|c|c|c|c|c|c|c|c|c|c|c|c|c|}
\hline \multirow{3}{*}{$\begin{array}{l}\text { Number } \\
\text { of Events }\end{array}$} & \multicolumn{12}{|c|}{ Ratios } \\
\hline & \multicolumn{3}{|c|}{$2.4 \mathrm{~Hz}$} & \multicolumn{3}{|c|}{$5.2 \mathrm{~Hz}$} & \multicolumn{3}{|c|}{$7.5 \mathrm{~Hz}$} & \multicolumn{3}{|c|}{$10 \mathrm{~Hz}$} \\
\hline & Mean & Std & $\mathbf{S} / \mathbf{M}$ & Mean & Std & $\mathbf{S} / \mathbf{M}$ & Mean & Std & $\mathbf{S} / \mathbf{M}$ & Mean & Std & $\mathbf{S} / \mathbf{M}$ \\
\hline 23 & 2.10 & .83 & .39 & 1.59 & .70 & .44 & 1.90 & .82 & .43 & 2.40 & 1.90 & .79 \\
\hline 21 & 1.25 & .68 & .54 & 2.02 & .71 & .35 & 1.91 & .88 & .46 & 6.01 & 2.95 & .49 \\
\hline 13 & 2.09 & 1.17 & .56 & 1.57 & .60 & .38 & 1.54 & .75 & .49 & 1.04 & .41 & .39 \\
\hline 14 & 8.30 & 2.44 & .29 & 1.34 & .53 & .40 & 2.02 & 1.01 & .50 & 1.34 & .50 & .37 \\
\hline 9 & 13.7 & 5.28 & .38 & 2.23 & .76 & .34 & 2.13 & .61 & .29 & .68 & .22 & .32 \\
\hline 22 & 18.0 & 8.29 & .46 & 3.68 & 1.26 & .34 & 3.02 & 1.40 & .46 & 1.80 & 1.28 & .71 \\
\hline 22 & 1.05 & .59 & .56 & 1.31 & .64 & .49 & 1.77 & 1.0 & .56 & 1.38 & .58 & .42 \\
\hline 7 & 3.67 & 1.73 & .47 & 1.74 & .37 & .21 & 2.06 & 1.12 & .54 & 1.87 & .70 & 37 \\
\hline 12 & 1.13 & .45 & .40 & 1.47 & .75 & .51 & 1.01 & .78 & .77 & .89 & .38 & .43 \\
\hline 5 & 2.94 & 1.39 & .47 & 9.67 & 2.57 & .26 & 3.51 & 1.72 & .49 & 4.18 & 1.39 & .33 \\
\hline 23 & 1.88 & .87 & .46 & 1.84 & .92 & .50 & 2.20 & 1.30 & .59 & 2.71 & 2.25 & \\
\hline
\end{tabular}

\section{Lower Hutt Array}

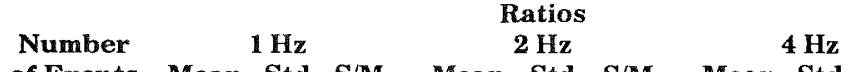

Site of Events Mean Std S/M Mean Std S/M Mean Std S/M

$\begin{array}{lrrrrrrrrrr}\text { L01 } & 12 & 2.2 & 1.2 & .55 & 3.3 & 1.9 & .57 & 4.5 & 2.5 & .57 \\ \text { L02 } & 26 & 2.1 & 1.1 & .53 & 3.6 & 2.0 & .56 & 2.0 & 1.2 & .62 \\ \text { L03 } & 9 & 2.1 & 0.7 & .34 & 2.5 & 1.0 & .42 & 1.1 & 0.4 & .33 \\ \text { L04 } & 17 & 5.4 & 3.9 & .72 & 5.4 & 1.9 & .36 & 3.7 & 2.1 & .56 \\ \text { L05 } & 10 & 6.9 & 3.6 & .53 & 5.0 & 3.1 & .62 & 3.9 & 1.8 & .45 \\ \text { L06 } & 16 & 6.3 & 3.3 & .52 & 6.3 & 3.4 & .54 & 1.6 & 0.6 & .39 \\ \text { L07 } & 10 & 2.2 & 1.1 & .50 & 2.9 & 2.0 & .68 & 0.8 & 0.3 & .37 \\ \text { L08 } & 17 & 2.7 & 1.2 & .46 & 2.8 & 1.9 & .68 & 2.5 & 1.3 & .53 \\ \text { L09 } & 3 & 8.5 & 0.4 & .05 & 12.2 & 8.0 & .66 & 3.4 & 1.1 & .31 \\ \text { L10 } & 5 & 9.8 & 6.5 & .67 & 11.0 & 5.7 & .52 & 1.6 & 0.6 & .35 \\ \text { L11 } & 13 & 6.1 & 3.5 & .57 & 5.6 & 2.6 & .45 & 1.3 & 0.6 & .44 \\ \text { L12 } & 13 & 5.8 & 3.1 & .53 & 6.0 & 2.1 & .36 & 1.9 & 0.7 & .38 \\ \text { L13 } & 8 & 2.4 & 1.0 & .43 & 4.4 & 2.0 & .45 & 1.6 & 1.1 & .70 \\ \text { L15 } & 9 & 5.7 & 1.4 & .24 & 6.5 & 2.0 & .31 & 1.6 & 0.7 & .43 \\ \text { L16 } & 14 & 3.5 & 1.7 & .50 & 16.3 & 10.0 & .61 & 4.7 & 2.1 & .45 \\ \text { L17 } & 9 & 15.8 & 6.0 & .38 & 11.7 & 3.4 & .29 & 5.6 & 3.0 & .54 \\ \text { L18 } & 9 & 14.3 & 5.1 & .36 & 6.9 & 3.4 & .49 & 4.7 & 2.8 & .59 \\ \text { L19 } & 10 & 0.8 & 0.6 & .71 & 1.6 & 1.1 & .72 & 2.2 & 1.0 & .44 \\ \text { L20 } & 12 & 2.4 & 0.8 & .35 & 3.3 & 1.3 & .39 & 2.0 & 0.8 & .42 \\ \text { L21 } & 9 & 3.1 & 1.1 & .35 & 3.5 & 1.3 & .38 & 3.6 & 2.2 & .61 \\ \text { L22 } & 10 & 4.3 & 1.0 & .23 & 3.6 & 1.7 & .46 & 4.4 & 2.3 & .52 \\ \text { L23 } & 10 & 5.0 & 1.2 & .24 & 4.5 & 2.3 & .50 & 2.4 & 1.4 & .59\end{array}$

Std $=$ Standard deviation

$\mathrm{S} / \mathrm{M}=$ Standard deviation divided by the mean 

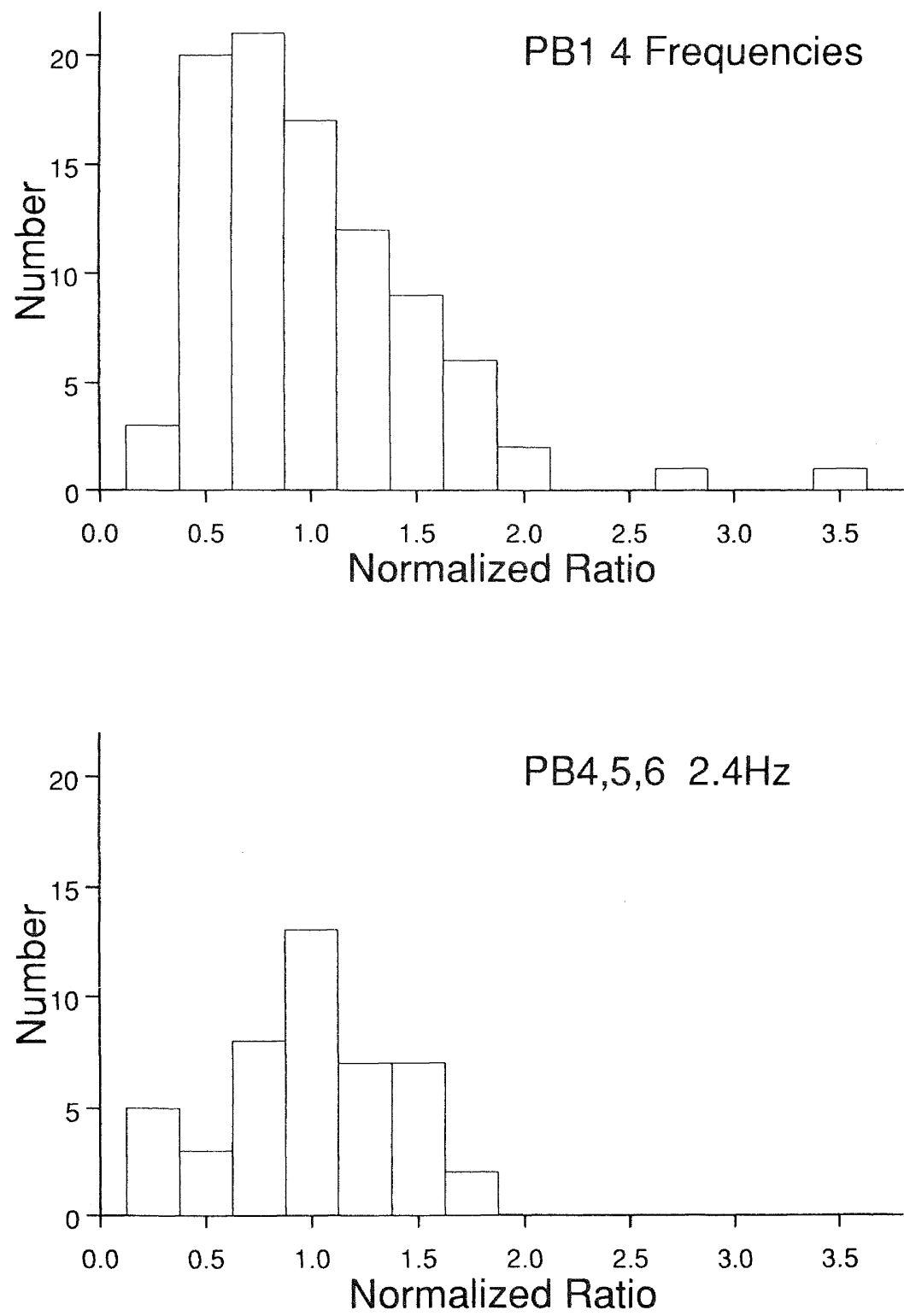

Figure 10. Distribution of spectral ratios about the mean for the Porirua array. Each ratio is normalised by the mean at that frequency so that the mean value is always equal to 1 .

Top: Summation of the 4 frequencies in Table 4 for station PB1.

Bottom: Summation of stations PB4, PB5, and PB6 at the frequency $2.4 \mathrm{~Hz}$. 


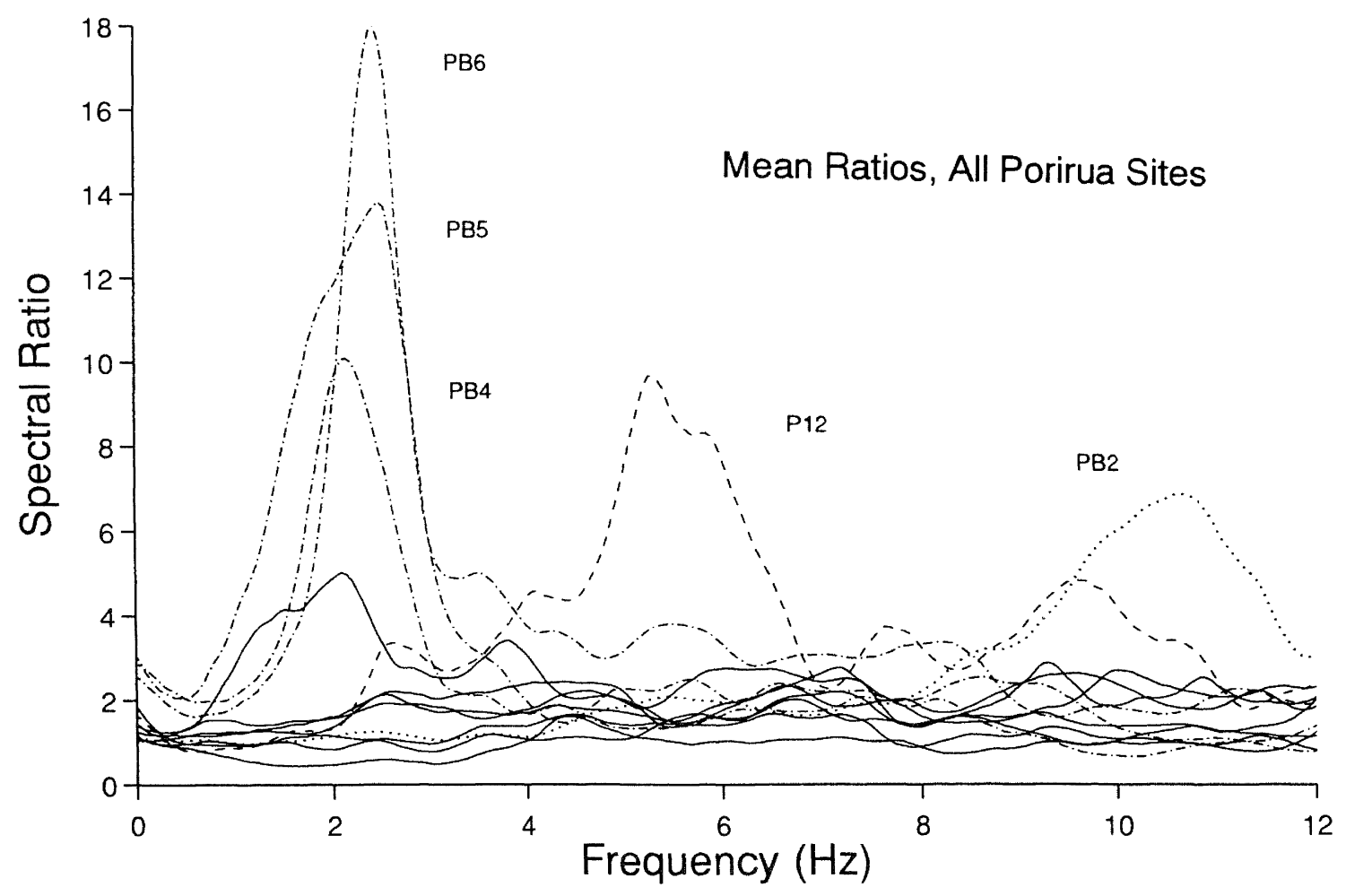

Figure 11. Mean Fourier spectral ratios for all Porirua sites. Spectra of all sites have been divided by the spectra of PB8. All three basin sites are plotted with a dot-dashed line.

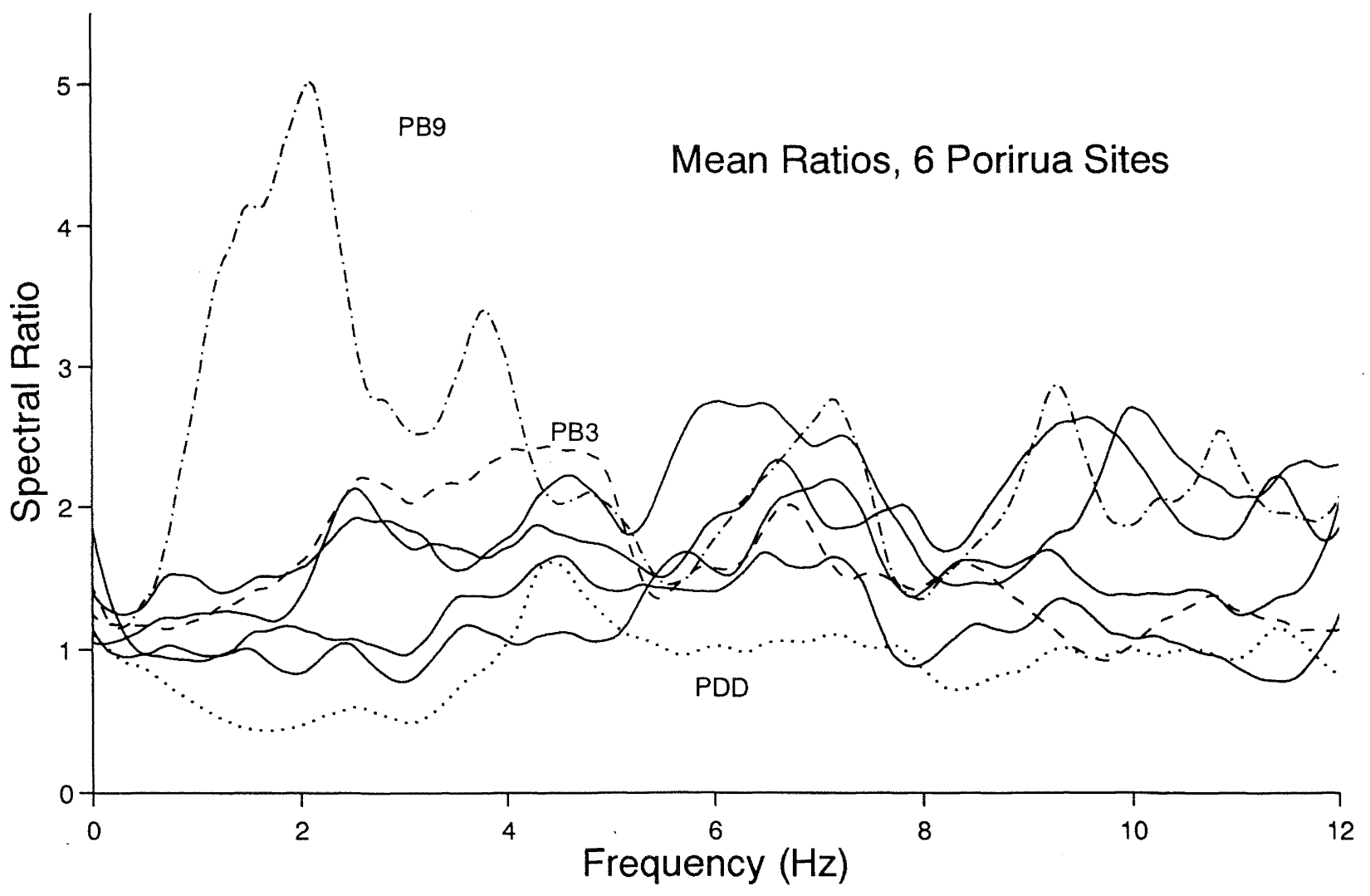

Figure 12. Mean Fourier spectral ratios for 6 Porirua sites and PDD, which is another rock site south of the Porirua array. 
None of the remaining sites show a clear resonance at a particular frequency. The ratios vary from no amplification up to nearly a factor of 3 . For comparison, PDD, a hard rock site 20 $\mathrm{km}$ south of the array, is plotted along with the other ratios. It is quieter than the reference site at most frequencies, and is a factor of two quieter in the frequency range $1-3 \mathrm{~Hz}$. Thus had PDD been used as the reference station, all spectral ratios would have been a factor of two higher in the $1-3 \mathrm{~Hz}$ range. Similar variations in hard rock sites have been reported in other studies [15]. The difference in the relative amplitude due to a difference in path length to PDD has been accounted for by scaling the spectral ratios by the ratio of the epicentral distance [3]. Distance scaling was not used for the Porirua stations because the difference in path lengths was very small.

Fig. 12 also highlights the rapid decrease in spectral ratio at the edges of the basin. One of the stations in this group (PB3) lies only $300 \mathrm{~m}$ outside the approximate flexible sediment boundary [4] but has a maximum ratio of just over two.

The mean spectral ratios for all Lower Hutt sites relative to site L14 are plotted in Fig. 13. It must be emphasised that different reference sites were used for the Porirua and Lower Hutt surveys because of the requirement that the reference site be near the other sites in the array. Thus the comparison of spectral ratios values between the surveys can be done only on a qualitative basis.

In the Lower Hutt survey, the only clear separation in the ratio values occurs between the 5 highest amplitude sites and the remainder of the stations. Most of the sites do not have any significant peaks in frequency but instead show amplifications over a broad frequency range. The spatial distribution of the maxima of the average spectral ratios in the frequency band $0.5-5 \mathrm{~Hz}$ is shown in Fig. 14. For each site, the average of the maximum mean value of the 2 horizontal components is plotted at the station location. Plotting the greater of the maxima of the $\mathrm{N}$ or $\mathrm{E}$ component or simply the maximum of a single component yields essentially the same result. However, for individual earthquakes the difference in the response of the north and east components can be quite large due to directional effects which are averaged out over many earthquakes. The spectral ratio of the reference site (L14) is defined as 1 and is plotted as a solid triangle. Note the increase in amplification over the short distance from L14 to L13. The figure shows the general increase in spectral ratio from the head of the valley to the foreshore, with higher amplification on the west side of the valley. This pattern is similar to the variation in sediment thickness in the valley, with the thicker sediments corresponding to the higher amplifications [4]. The highest amplifications were recorded in Wainuiomata and Naenae. The dashed lines in the figure are diagramatic contours of spectral ratios of $<6$, $>10$, and $>15$.

The ratios are best examined by separating the stations into groups based on the dashed lines in Fig. 14. Since the increase in amplification is gradual, the exact boundaries between the groups is somewhat arbitrary. Fig. 15 (top) plots the 4 firm sites. This shows the variation in "rock sites". The quietest site (L14) was chosen as the reference, so the ratios for the other sites are all at least 1 and are as high as 3. Some of the amplification relative to $\mathrm{L} 14$ could be due to topographic effects, as sites L07, L08, and L19 are all on the steep hills on the sides of the valley. In contrast, L14 is at a much lower elevation at the edge of the valley.
The ratios for the class $B$ sites (ie. those north of the first contour in Fig. 14) are shown in Fig. 15 (bottom). These ratios overlap with the firm sites. The quietest sites have responses similar to the rock sites while those with the highest amplification are clearly different from the rock sites. In general, the amplification occurs over a broad frequency band from 0.5 to $5 \mathrm{~Hz}$, although the two sites nearest the valley edge (L01 and L13) exhibit amplification primarily above $2 \mathrm{~Hz}$. Small peaks at particular frequencies may not be significant.

The ratios for the class $\mathrm{C}$ sites (ie. those sites between the first and second contours in Fig. 14) are shown in Fig. 16. These ratios overlap with those from the class B sites but are clearly higher in amplification than the firm site ratios. As the amplification increases, the higher frequencies appear to be attenuated, so the amplification occurs over a narrower frequency band. Once again there are no obvious resonant frequencies.

Fig. 17 plots the class D site ratios. Note that the plotting scale has been changed. All 5 of these sites have amplifications greater than the class $\mathrm{C}$ sites. Two of the sites, L16 (Wainuiomata) and L18 (Naenae), exhibit resonance behaviour at $2 \mathrm{~Hz}$ and $1 \mathrm{~Hz}$ respectively, similar to the basin sites in Porirua. Both of these sites appear to be on 10-30 m thick flexible sediment overlying much firmer material. While the other sites have peaks at some frequencies, the peaks are not present for all earthquakes. For example, the peaks for L17 may be due to resonances at two different frequencies (see Fig. 9), as the shear wave velocity results would suggest [13]

\section{PARTICLE MOTION}

The 3-dimensional ground motion was examined at the Porirua basin sites in an attempt to characterise the resonance in the basin. The same 10 second $S$ wave segment as used in the frequency analysis was bandpass filtered from $1-3 \mathrm{~Hz}$. The frequency band was chosen to correspond to the width of the resonance peak in the basin site spectra. Fig. 18 shows an example of the horizontal particle motion for PB6 for six different earthquakes while Fig. 19 shows four of the same six earthquakes for station PB4. Only the horizontal components are shown because the particle motion in the $1-3 \mathrm{~Hz}$ frequency band is almost completely horizontal.

The horizontal particle motion varies considerably between events and between different stations for the same event. In the examples shown, the particle motions on the left of each figure were generated by three earthquakes from the same after-shock sequence. Thus the earthquakes occurred at essentially the same distance $(150 \mathrm{~km})$, and azimuth, and had depths vary-ing by no more than $5 \mathrm{~km}$, based on a detailed study of the aftershocks (R. Robinson, personal communication). The particle motions on the right of Fig. 18 were generated by three events just offshore at a similar distance and azimuth, though perhaps at a greater depth than the events on the left (see Fig. 3 for map of locations). The lack of coincidence in particle motion between the six events shows that there is not a simple relationship between earthquake azimuth and particle motion. The group of events on the right side of Fig. 18 show similar particle motions whereas the particle motions from the perhaps even more closely spaced events on the left appear unrelated. The focal mechanism may be different between the events at 10 and $15 \mathrm{~km}$ depth in the aftershock sequence, but the mechanism would be expected to be the same for the two events at the same depth. The righthand side earthquakes are all offshore and therefore there is a larger uncertainty in their location. 


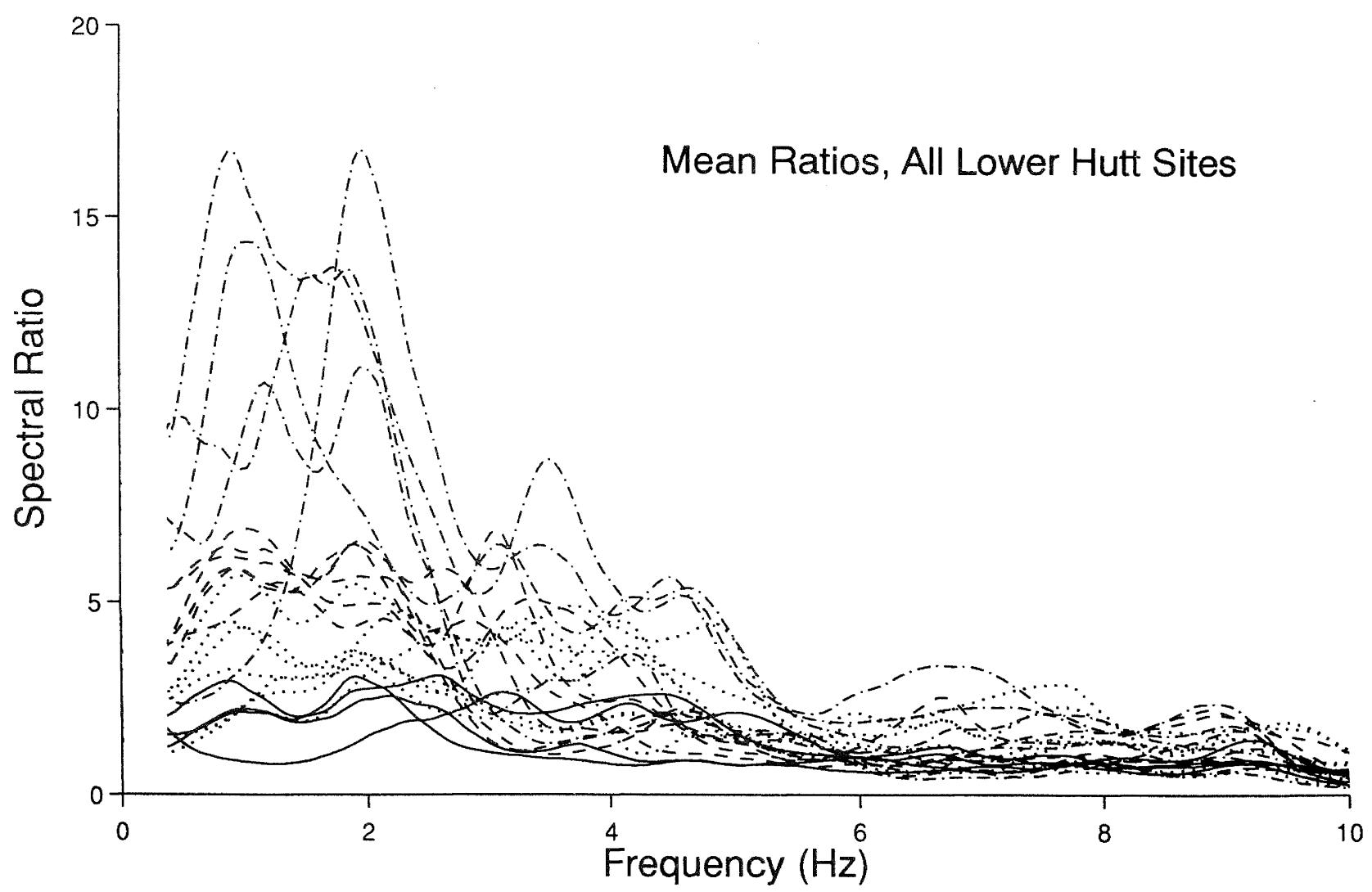

Figure 13. Mean Fourier spectral ratios for the north component of all Lower Hutt sites. Spectra of all sites have been divided by the spectra of site L14. Means are divided into 4 classes based on maximum Fourier spectral ratio (Fsr). Solid line - firm sites, dotted line - class B (Fsr 3-5), dashed line - class $C$ (Fsr 6-10), dot-dashed line - class D (Fsr 12-17).

Stephenson $[11,12]$ has suggested that a basin can resonate with the normal modes of a cylinder; but with multiple, nearly degenerate modes, the resulting oscillation can change with time, as in the lefthand example in Fig. 18. There also does not appear to be a simple relationship between the particle motions of the three basin sites (compare Figs. 18 and 19). Further work is required with a much closer station spacing to successfully study the variation of such modes across the basin.

\section{DISCUSSION}

Spectral ratios for resonant sites similar to those in the Porirua basin have been calculated in Leninakan from aftershocks of the 1988 Armenian earthquake [3]. Leninakan was about $35 \mathrm{~km}$ distant from the magnitude 6.8 main shock. No data exists to make a strong motion comparison of soft and rock sites there, but the damage distribution correlates with the spectral ratios of the aftershocks. The frequency of the peak in the spectral ratio was slightly lower than the resonance frequency of the heavily damaged buildings. This is explainable if the period of the damaged structures lengthened into the soil resonance periods at the onset of damage. Thus the buildings may have had a more non-linear response than did the soil. While the amplification was no doubt less than that measured by the spectral ratios, greater damage did occur in those regions, and the weak motion peak period was similar to the natural period of the buildings with the greatest damage.

We expect therefore that the resonance frequency for strong ground motions in the Porirua basin and Lower Hutt sites L16 and L18 will be the same as for weak motions. The peak frequencies recorded in the Porirua survey were the same as predicted by the cylindrical mode analysis of Stephenson and Barker [13] which is nearly the same as the frequency predicted by a simple calculation of the vertical $S$ wave propagation time in the center of the basin. However the occurrence of the same frequency at the edge of the basin (PB6) does not match the vertical transit time model. A similar case of the same frequency being recorded at the center and edge of a basin was reported by King and Tucker [9]. The Porirua basin resonance seems to be easily excited since it is evident in all the events studied. There were no events recorded at a distance less than $25 \mathrm{~km}$ so it was not possible to find the minimum distance at which an earthquake can still excite a basin resonance. 


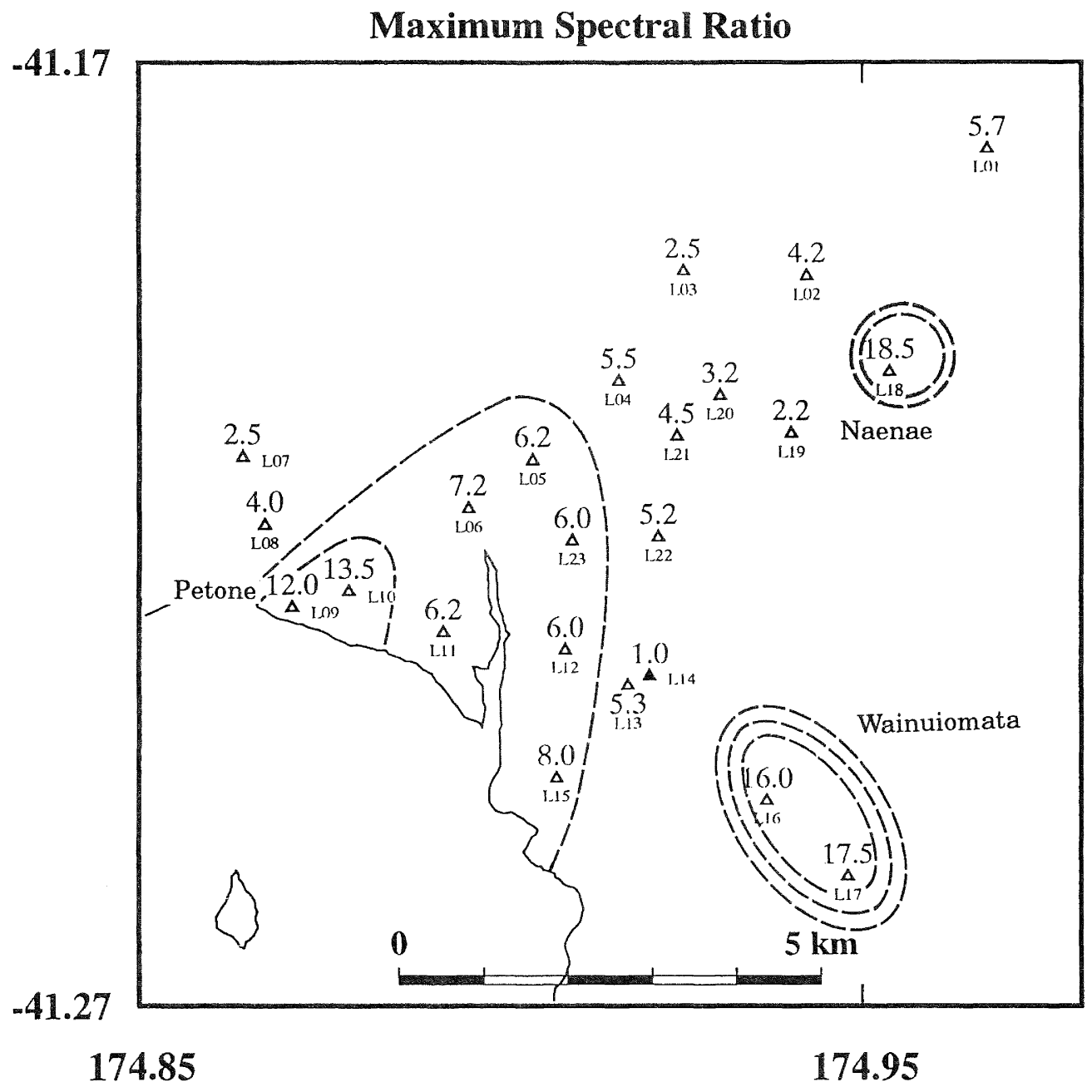

Figure 14. Map of the maximum value of the mean spectral ratio for each site in the Hutt Valley. The number plotted is an average of the north and east component. The solid triangle (L14) is the reference site and thus the ratio there is 1 by definition. L03, L07, L08, and L19 are the other firm sites. Dashed lines are contours of spectral ratios $<6,>10$, and $>15$, and separate the B, C, and D classes displayed in the spectral ratio figures. 

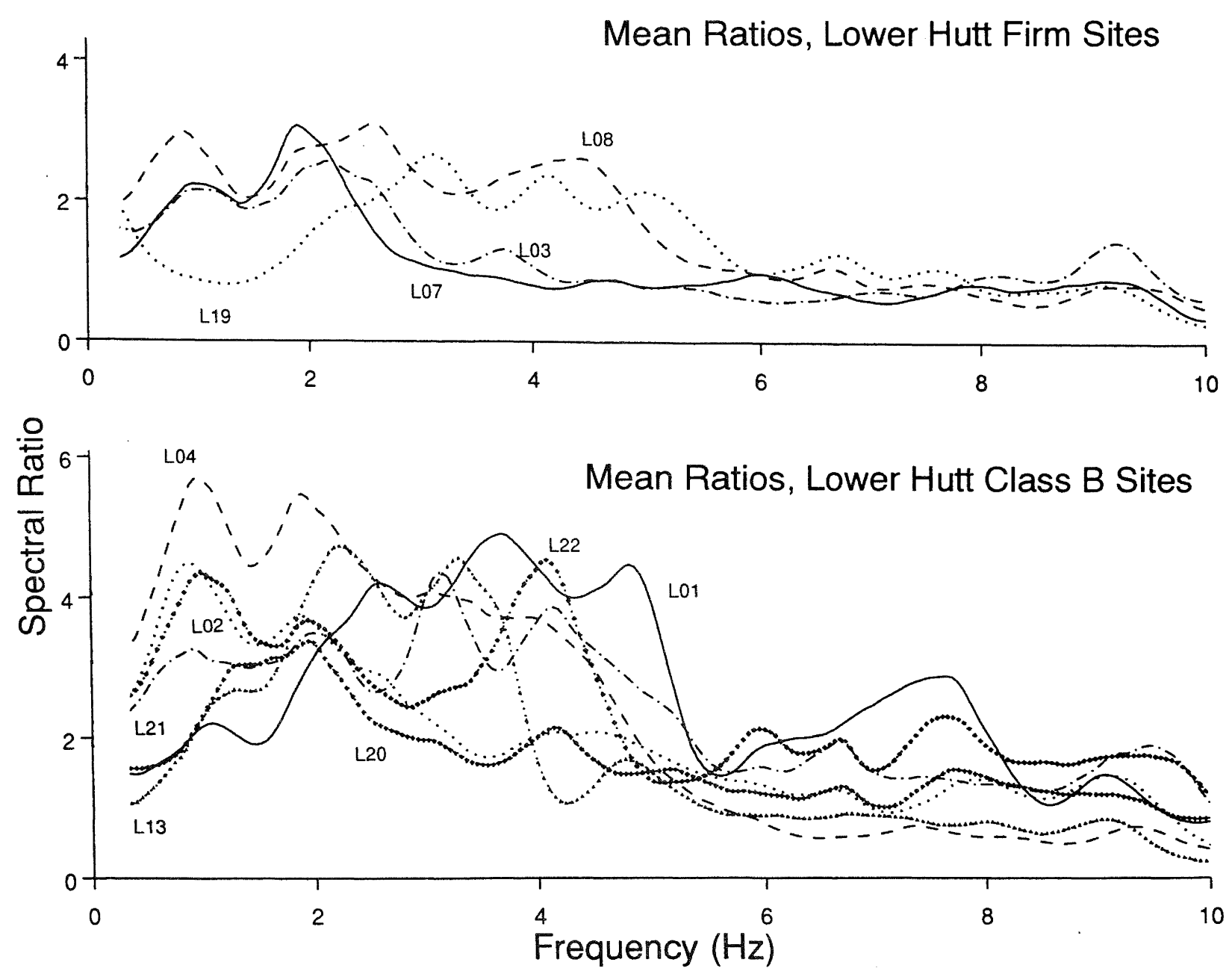

Figure 15. Top: Mean Fourier spectral ratios for the 4 firm Lower Hutt sites.

Bottom: Mean Fourier spectral ratios for the 7 class B sites.

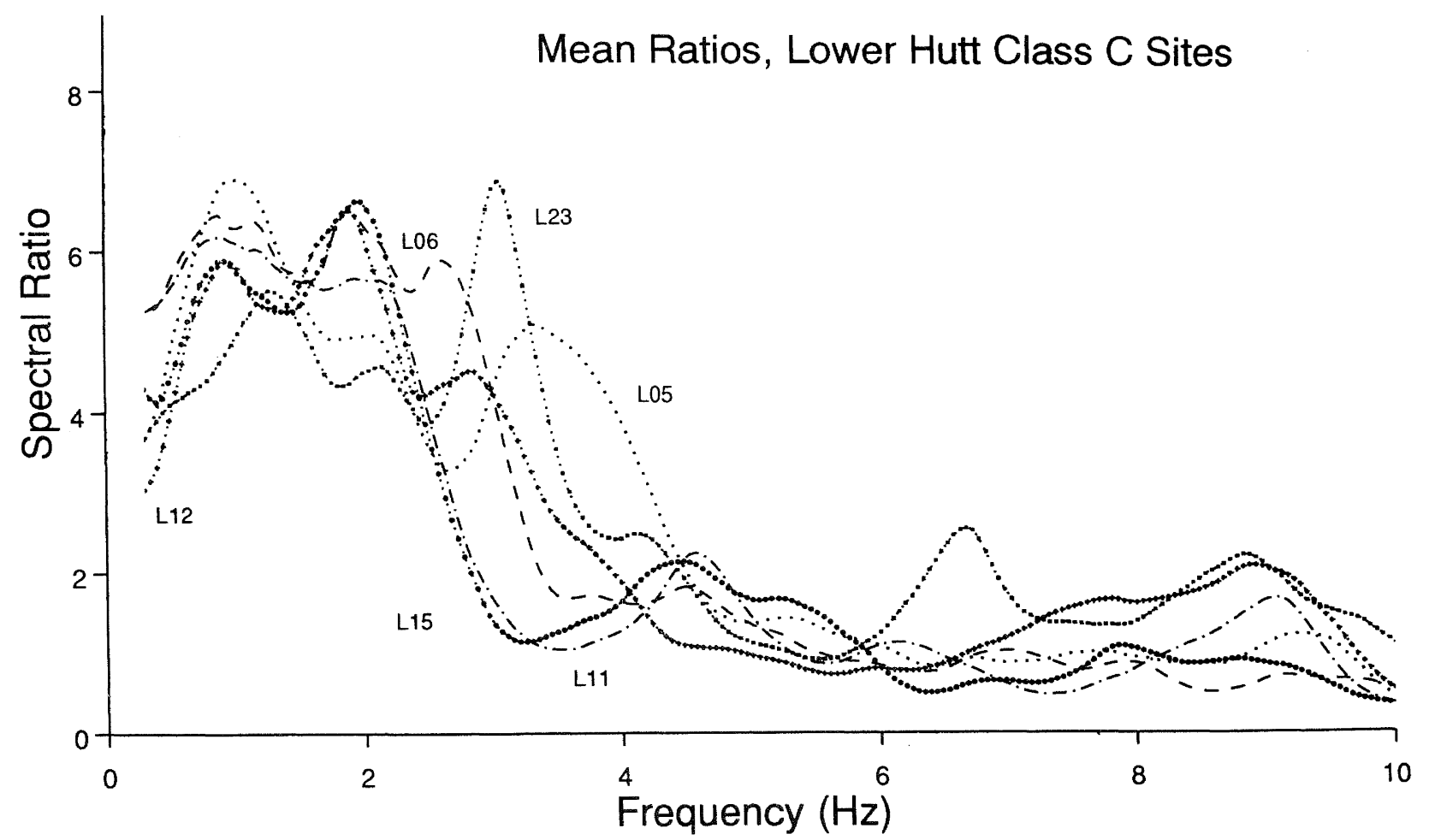

Figure 16. Mean Fourier spectral ratios for the 6 class C sites. 


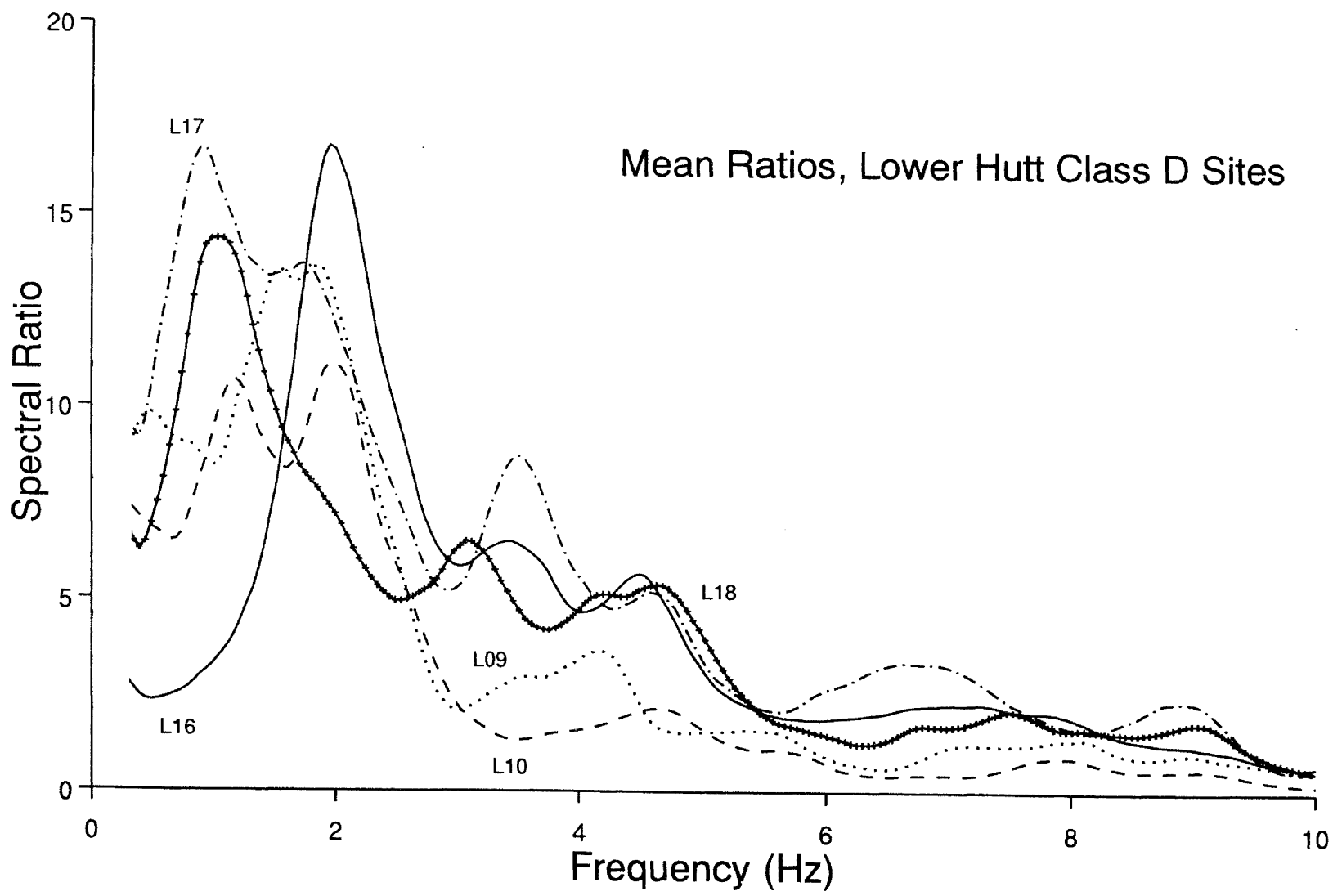

Figure 17. Mean Fourier spectral ratios for the 5 class D sites. Note that the ratio scale has been doubled in this figure relative to the previous 3 figures.

At the other sites where the average response shows amplification over a broad frequency range, the response due to a particular earthquake can be quite different. This difference must be kept in mind when comparing the average results in this study to individual, though larger, events studied in the companion paper by Sritharan and McVerry [10]. Particular frequencies may be excited much more than the average so any building with a natural period within the range of amplified frequencies is potentially at risk.

The spectral ratio cannot be directly correlated with the increase in peak acceleration or velocity since the spectral ratio is strongly influenced by the duration of the increased shaking. In general the spectral ratio increases much faster than does the peak velocity or acceleration. For example, at one resonant site a spectral ratio of 18 corresponds to an increase in the peak ground velocity by a factor of 5 while a spectral ratio of 28 corresponds to an increase in peak ground velocity of a factor of 6. Many cycles of moderate motion (as shown in the seismic traces in figs. 5-7) may excite resonances in buildings with the same natural period so that in some cases the high spectral ratio can be more important than a moderate increase in peak acceleration.
The 4 classes of amplification based on the contours in Fig. 14 are closely related to the zones on the microzoning map that was produced from all available data (Fig. 20, from [16]). The firm sites are all in zone 1 and the class B sites are all in zone 2 except for the site with the highest ratio in that category (LO4) which is just inside zone 3-4 on the map. Three of the class C sites are in zone 3-4 while the remaining 3 are in the unresolved part of the zone 5 region. All class D sites are in the zone 5 region.

The lack of a complete coincidence between the class $\mathrm{C}$ and zone 3-4 sites is due to the apparent difference between the microearthquake and strong motion records at site L05. There is a strong long period response for periods in excess of one second seen on some strong motion records [10] that is not visible on the microearthquake records. It is possible that a large earthquake, which has a larger relative amount of low frequency energy, may excite a strong long period response within the valley. 


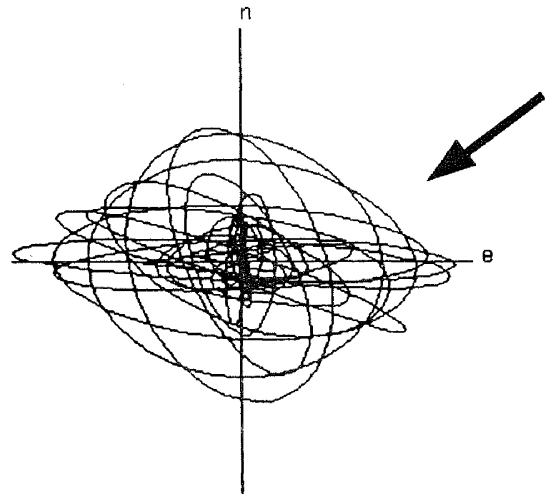

Date

09/06/90

Time

Depth

10.5

$11 / 06 / 90 \quad 10: 58$

25
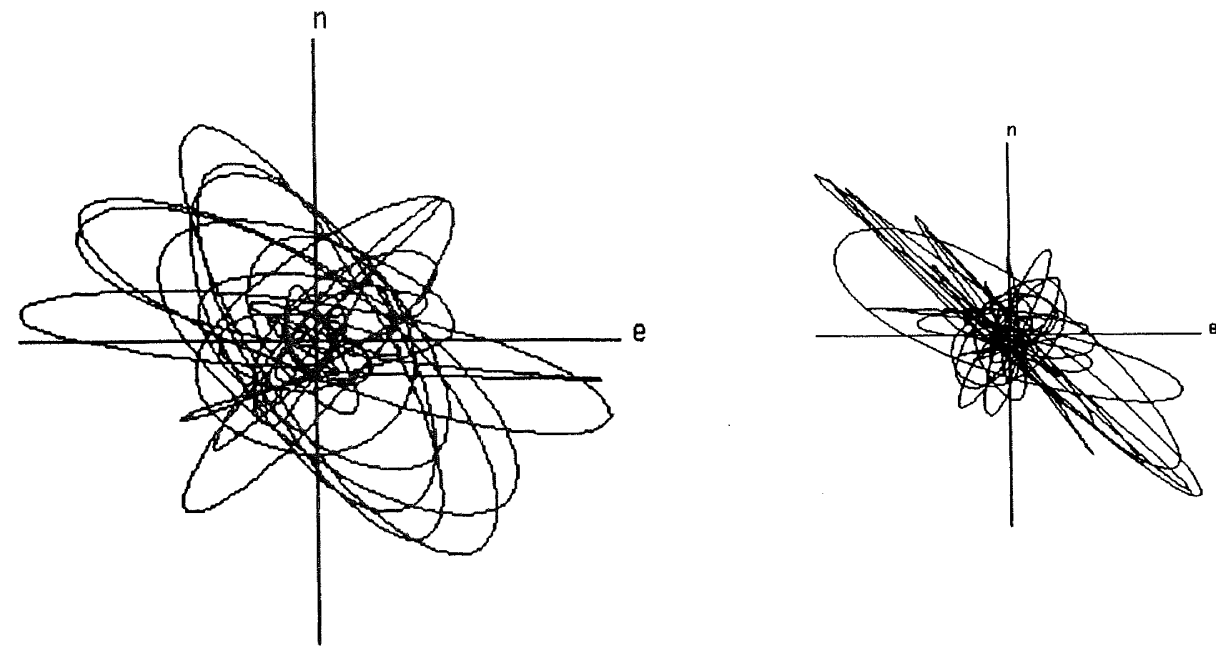

$17 / 06 / 90 \quad 10: 23 \quad 15.3$

$12 / 06 / 90$

$12: 21$
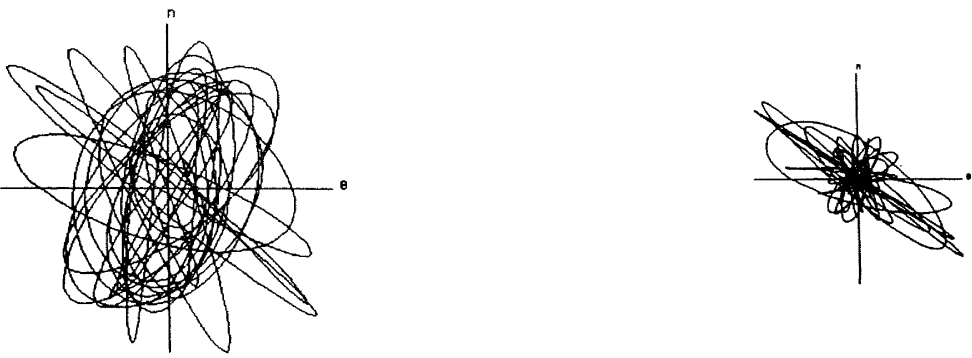

$17 / 06 / 90$

$16: 31$

15.2

$16 / 06 / 90 \quad 16: 39$

Figure 18. Particle motion in the horizontal plane for six earthquakes as recorded at site PB6. The epicentres for the 3 earthquakes in each column are nearly the same. The arrow in the horizontal plane points from the earthquake to the station. The scale is the same for each earthquake. See Fig. 5 for the seismogram of the top left earthquake. 


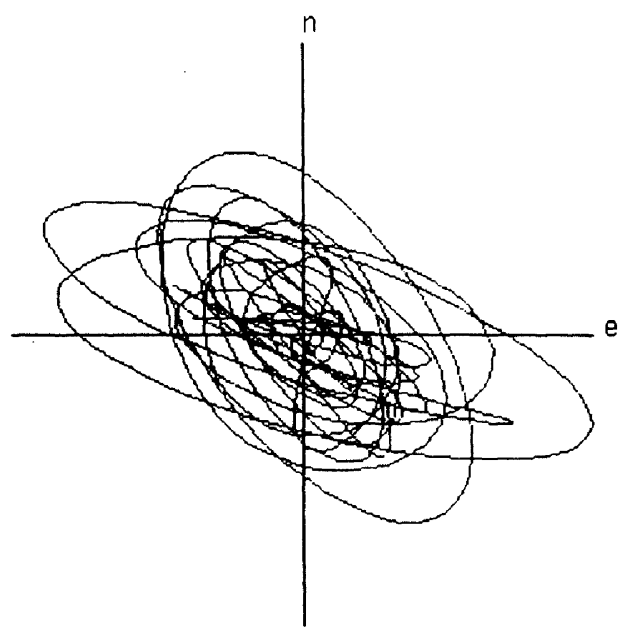

Date Time Depth

09/06/90 18:18 $\quad 10.5$

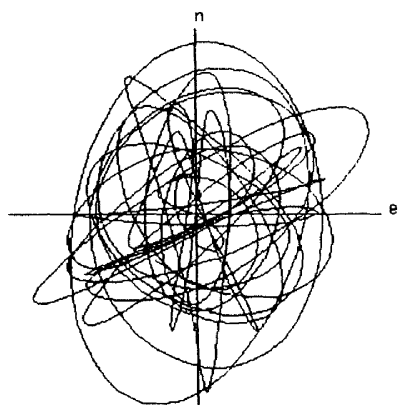

$17 / 06 / 90 \quad 10: 23 \quad 15.3$
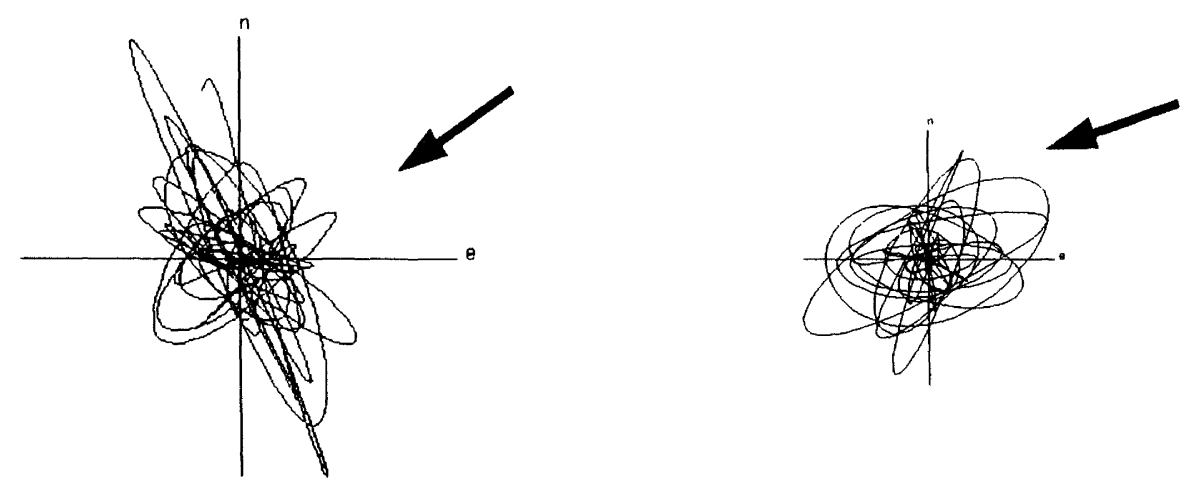

$17 / 06 / 90 \quad 16: 31 \quad 15.2$

$16 / 06 / 90 \quad 16: 39 \quad 32$

Figure 19. Particle motion in the horizontal plane for four earthquakes as recorded at site PB4. The earthquakes are the same as in Fig. 18. 
For the microearthquake data, the ratio values below about 0.5 $\mathrm{Hz}$ are not meaningful because of the limited response of the seismometers at low frequencies and the smoothing applied to the spectra. It was possible to calculate a spectral ratio down to $0.2 \mathrm{~Hz}$ using a longer sampling interval $(40 \mathrm{sec})$ for the largest earthquake in the data set. For this earthquake the ratio at 0.2 $\mathrm{Hz}$ was similar to the ratio at $0.5 \mathrm{~Hz}$ for most stations. However, there is not enough long period energy in the smaller earthquakes used in the averaging to extend all the composite spectra to low frequencies.

The microearthquake records show that site L05 has a much lower amplification than sites in the class $\mathrm{D}$ region up to about $3 \mathrm{~Hz}$. Above this frequency the ground motion is attenuated in the Petone area (class D region). This is the point on Fig. 13 where the dot-dashed lines (class $D$ ) begin to drop below the dashed lines (class $\mathrm{C}$ ). Thus at high frequencies the amplification will be higher at the class $C$ sites though it is still a lower amplification than at low frequencies. In the intermediate frequency range of 0.5 to $2 \mathrm{~Hz}$, the microearthquake results suggest that the highest amplification will occur in Petone. The values on the map in Fig. 14 are based on the highest amplification at any frequency since the highest amplification at a particular site was deemed to be the most important for zoning purposes. Site L11 also recorded a lower amplification than would be expected based on the zoning in Fig. 20. This may be true because the site is next to a bend in the Hutt River and may be sitting on dense gravels deposited by the river.

Except for the just mentioned differences at long period, the results for the strong and weak motion studies are very similar. This suggests that the weak motion conclusions can be extrapolated to larger motions. Intensity maps based on weak motion data in the San Francisco area anticipated all the areas outside the epicentral region that experienced strong shaking during the 1989 Loma Prieta earthquake [2].

Small amplifications (factors of 2-3) have been shown to persist to $0.7 \mathrm{~g}$ in soft soils in California [7] and to $0.2 \mathrm{~g}$ in Garm, USSR [14]. However there was a decrease in the maximum spectral ratio from 8 to 3 between aftershocks and the mainshock of the 1989 Loma Prieta earthquake at one soft site in California [8]. This is an extreme example of non-linear behaviour as the soils liquified after 5 seconds of shaking.

A spectral amplification of 15 as recorded at the flexible sediment sites in Wainuiomata, Naenae, and Petone cannot be expected to persist to very large motions. However a high amplification of small ground motions means significant local damage could result from a moderate earthquake that would cause no damage at a firm site. If the comparison of strong and weak motions in other areas can be applied to New Zealand, small amplification factors of 2-5 may remain the same for strong ground motion while the large amplifications measured for microearthquakes at the class D sites in Lower Hutt and the basin sites in Porirua are likely to be decreased for the larger earthquakes. The high amplifications for these sites thus must be considered as an upper bound on the shaking to be expected in a large earthquake. Nevertheless, smaller moderate amplifications of damaging shaking may be quite significant.

Microearthquake recording of ground motion is probably best for determining regions of greater shaking, rather than predicting absolute levels. The technique has the advantage that variations in ground motion can be measured directly at little expense and with little disruption of the soil. This is particularly useful in areas where drilling is not viable. A reconnaiss- ance survey can also determine areas where more detailed study is required and, as shown here, can complement soil property measurements and numerical modeling.

\section{CONCLUSIONS}

The relative ground response due to microearthquakes has been examined at 24 sites in the Lower Hutt region and 12 sites in the Porirua area. In Porirua there was greatly increased shaking at three sites, two of which were previously identified as flexible sediment sites (underlain by $10-15 \mathrm{~m}$ of soft, fine-grained material). The third site was just outside the mapped flexible sediments. The amplification at these sites occurred in a narrow frequency band of $1-3 \mathrm{~Hz}$ and resulted in average Fourier spectral ratios (Fsr) of 10-18. A spectral ratio of 18 corresponds to an increase in peak ground velocity of a factor of 5 . Three other sites had spectral ratios of greater than 5 at some frequency while the remaining sites varied from no amplification to factors of 3 relative to the rock reference site.

In Lower Hutt there was a gradual increase in shaking when progressing from the top of the Hutt Valley to the Petone foreshore, in a pattern similar to the increase in total sediment thickness and near-surface flexible sediment. The response at the northern-most sites was similar to the response at the rock sites on the side of the valley (Fourier spectral ratios of 2-4) while the Fourier spectral ratios reach 14 in Petone. The highest amplifications were recorded at two sites in Wainuiomata $(\mathrm{Fsr}=16$ to 18$)$. A small region in Naenae also had a high amplification (Fsr $=15$ ). Both the Wainuiomata and Naenae sites were underlain by $>10 \mathrm{~m}$ of soft fine-grained sediment with $S$ wave velocities $<200 \mathrm{~m} / \mathrm{s}$.

The amplification at most Lower Hutt sites occurred over a broad frequency band from $0.5 \mathrm{~Hz}$ to up to $5 \mathrm{~Hz}$, with the high frequency limit of the band decreasing as the spectral ratio in the band increased. Two sites (one in Naenae, one in Wainuiomata) exhibited a very narrow frequency response similar to three sites on flexible sediments in the Porirua basin. Both the Naenae and Wainuiomata sites also appear to be on flexible sediments. The peak frequency at Wainuiomata was $2 \mathrm{~Hz}$ while it was $1 \mathrm{~Hz}$ at Naenae.

Results from studies in other areas suggest that the frequency of amplified shaking remains the same for certain large damaging earthquakes. However the amount of amplification for large ground motions is still an unresolved question. An amplification of 18 is unlikely to persist to very large motions as the flexible sediments are expected to lose their cohesion during strong shaking, but a high amplification of small ground motions means local damage could result from a moderate earthquake that would cause no damage at a firm site.

\section{ACKNOWLEDGEMENTS}

The authors wish to thank Mark Chadwick for much assistance with the data collection and initial processing. John Haines chose and obtained permission for most of the Lower Hutt sites, and assisted in the data collection. Ken Gledhill's knowledge of the EARSS software was crucial for determining triggering parameters. Wayne Richardson, Jimmy Millar, and Ray Maunder also assisted with the field work, and Helen Anderson assisted with the data processing. The text was greatly improved by reviews by Russ Van Dissen, Bill Stephenson, and Nick Perrin. This research was partially funded by the Wellington Regional Council, and the authors graciously acknowledge their release of the data for publication. 


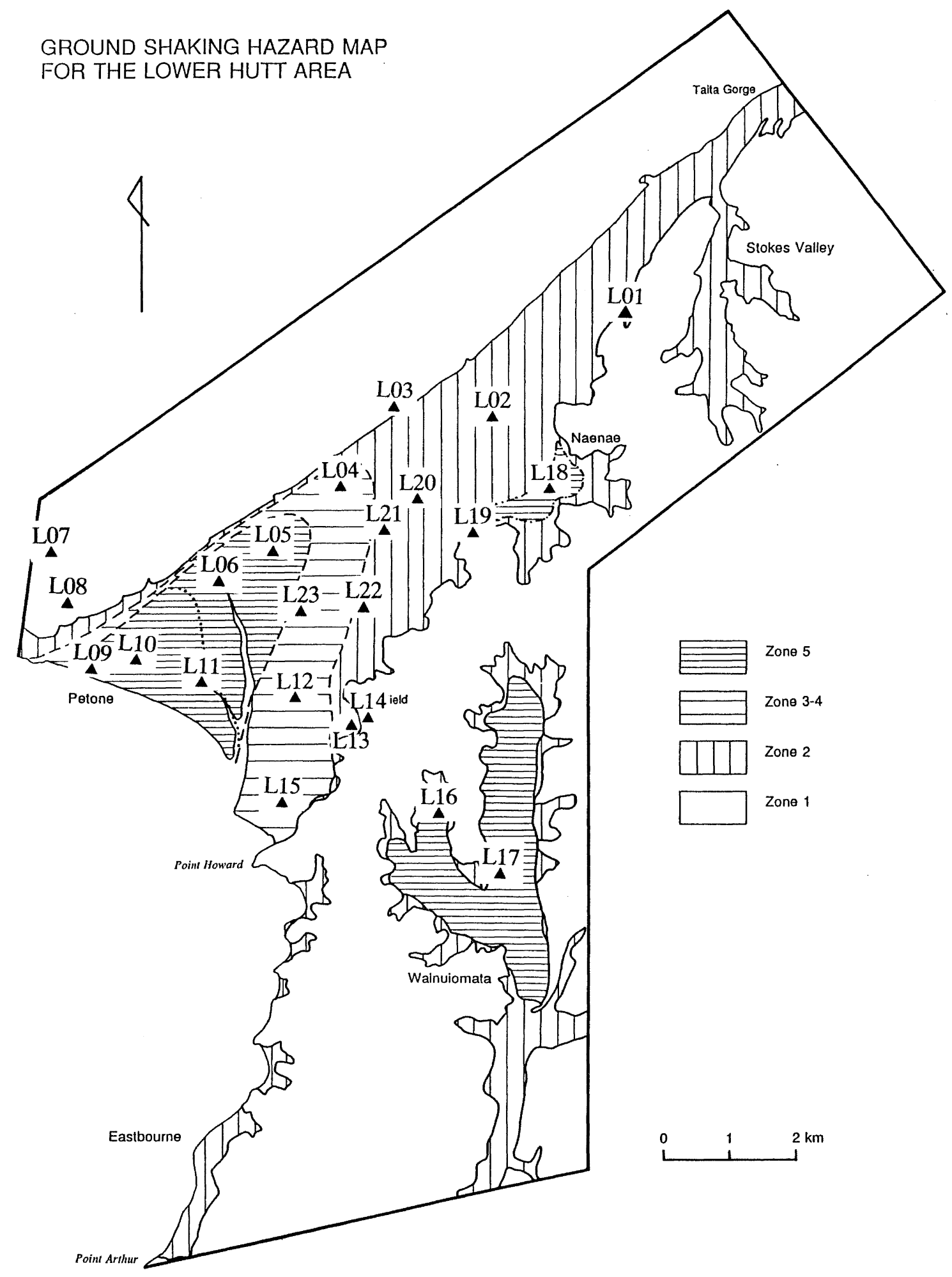

Figure 20. Lower Hutt recording stations plotted on microzoning map from [16]. Dotted line is possible separation of zone 5 into long and short period shaking. 


\section{REFERENCES}

1. Borcherdt, R.D. 1970. "Effects of local geology on ground motion near San Francisco Bay", Bull. Seism. Soc. Am. 60: 29-61.

2. Borcherdt, R.D. 1991. "On the observation, characterization, and predictive GIS mapping of strong ground shaking for seismic zonation (A case study in the San Francisco Bay region, California)", Pacific Conference on Earthquake Engineering Proceedings, 1-24.

3. Borcherdt, R., Glassmoyer, G., Andrews, M., Cranswick, E. 1989. "Effects of site conditions on ground motion and damage", Earthquake Spectra, special supple-ment, August, 1989, 23-42.

4. Dellow, G.D., Read, S.A.L, Begg, J.G., Van Dissen, R.J., Perrin, N.D., 1992, "Distribution of geological materials in Lower Hutt and Porirua, New Zealand: a component of a ground shaking hazard assessment", Bull. New Zealand National Society for Earthquake Engineering, this volume.

5. Gledhill, K.R., Randall, M.J., Chadwick, M.P. 1991. "The EARSS seismograph: system description and field trials", Bull. Seism. Soc. Am. 81: 1380-1390.

6. Haines, A.J. 1990. "Intensities felt in Wellington from (13 May) Dannevirke earthquake (abstract)", New Zealand Geophysical Society meeting, August, 1990.

7. Jarpe, S.P., Cramer, C.H., Tucker, B.E., Shakal, A.F. 1988. "A comparison of observations of ground response to weak and strong ground motion at Coalinga", California, Bull. Seism. Soc. Am. 78: 421-435.

8. Jarpe, S.P., Hutchings, L.J., Hauk, T.F., Shakal, A.F. 1989. "Selected strong- and weak-motion data from the Loma Prieta earthquake sequence", Seismological Research Letters 60: 167-176.
9. King, J.L., Tucker, B.E. 1984. "Observed variations of earthquake motion across a sediment-filled valley", Bull. Seism. Soc. Am. 74: 137-151.

10. Sritharan, S., McVerry, G.H. 1992. "Microzone effects in the Hutt Valley in records from a strong motion accelerograph array", Bull. New Zealand National Society for Earthquake Engineering, this volume.

11. Stephenson, W.R. 1989. "Normal modes of a "cylindrical valley' of alluvium", Bull. New Zealand National Society for Earthquake Engineering 22: 76-80.

12. Stephenson, W.R. 1989. "Observation of a directed response in soil driven by transverse rock motion", Bull. New Zealand National Society for Earthquake Engineering 22: 81-89.

13. Stephenson, W.R., Barker, P.R., "Evaluation of sediment properties in the Lower Hutt and Porirua areas by means of cone and seismic cone penetration tests", Bull. New Zealand National Society for Earthquake Engineering, this volume.

14. Tucker, B.E., King, J.L. 1984. "Dependence of sediment-filled valley response on input amplitude and valley properties", Bull. Seism. Soc. Am. 74: 153-165.

15. Tucker, B.E., King, J.L., Hatzfeld, D., Nersesov, I.L. 1984. "Observations of hard-rock site effects", Bull. Seism. Soc. Am. 74: 121-136.

16. Van Dissen, R.J., Taber, J.J., Stephenson, W.R., Sritharan, S., Read, S.A.L., McVerry, G.H., Dellow, G.D., Barker, P.R., 1992, "Earthquake ground shaking hazard assessment for the Lower Hutt and Porirua areas", Bull. New Zealand National Society for Earthquake Engineering, this volume. 


\section{APPENDIX}

Fourier spectral ratio plots for all events at selected stations.

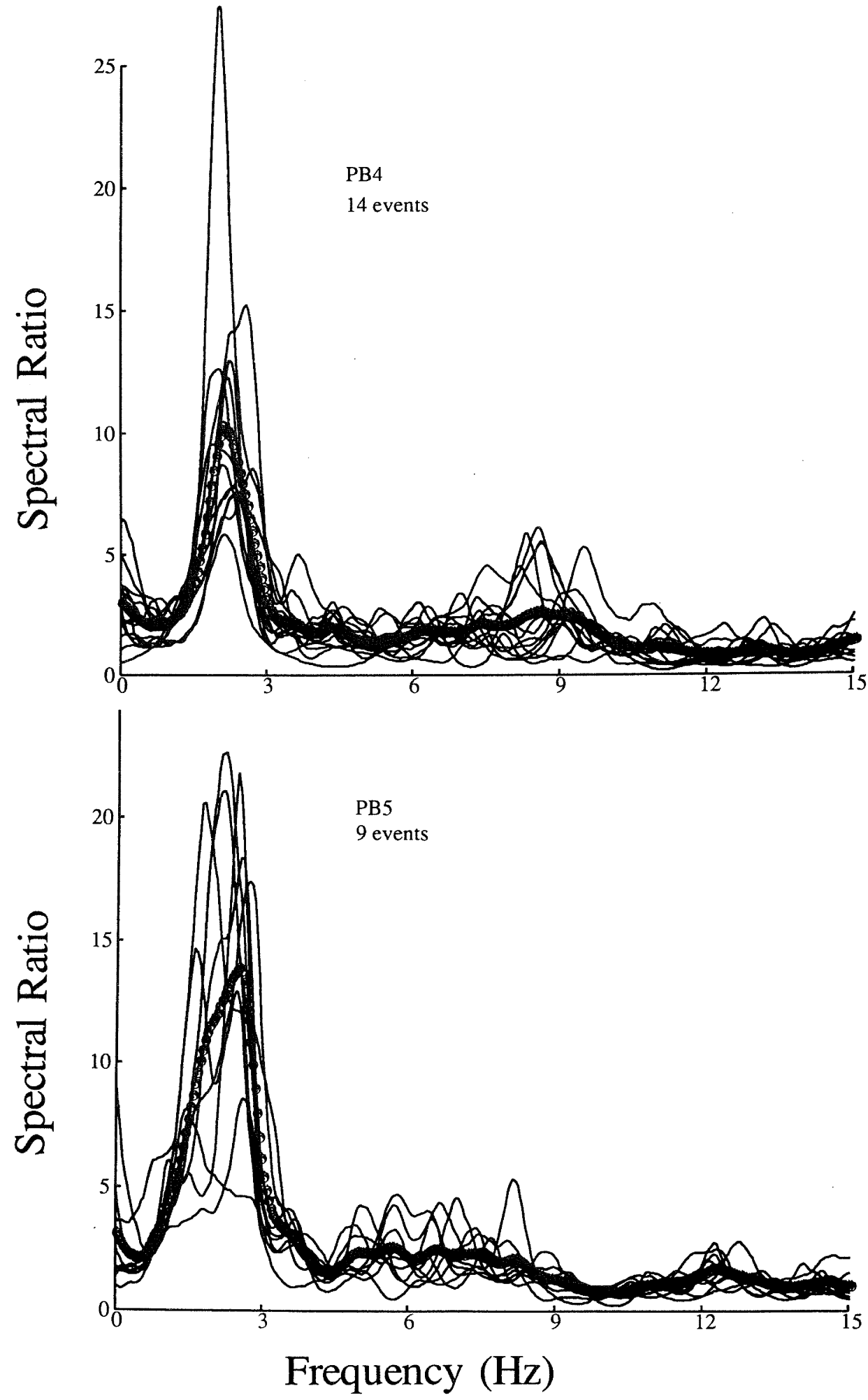

Figure A1. Fourier spectral ratios (FSR) of the N-S component of sites PB4 and PB5. Dark line is the mean plotted in Fig. 11. 

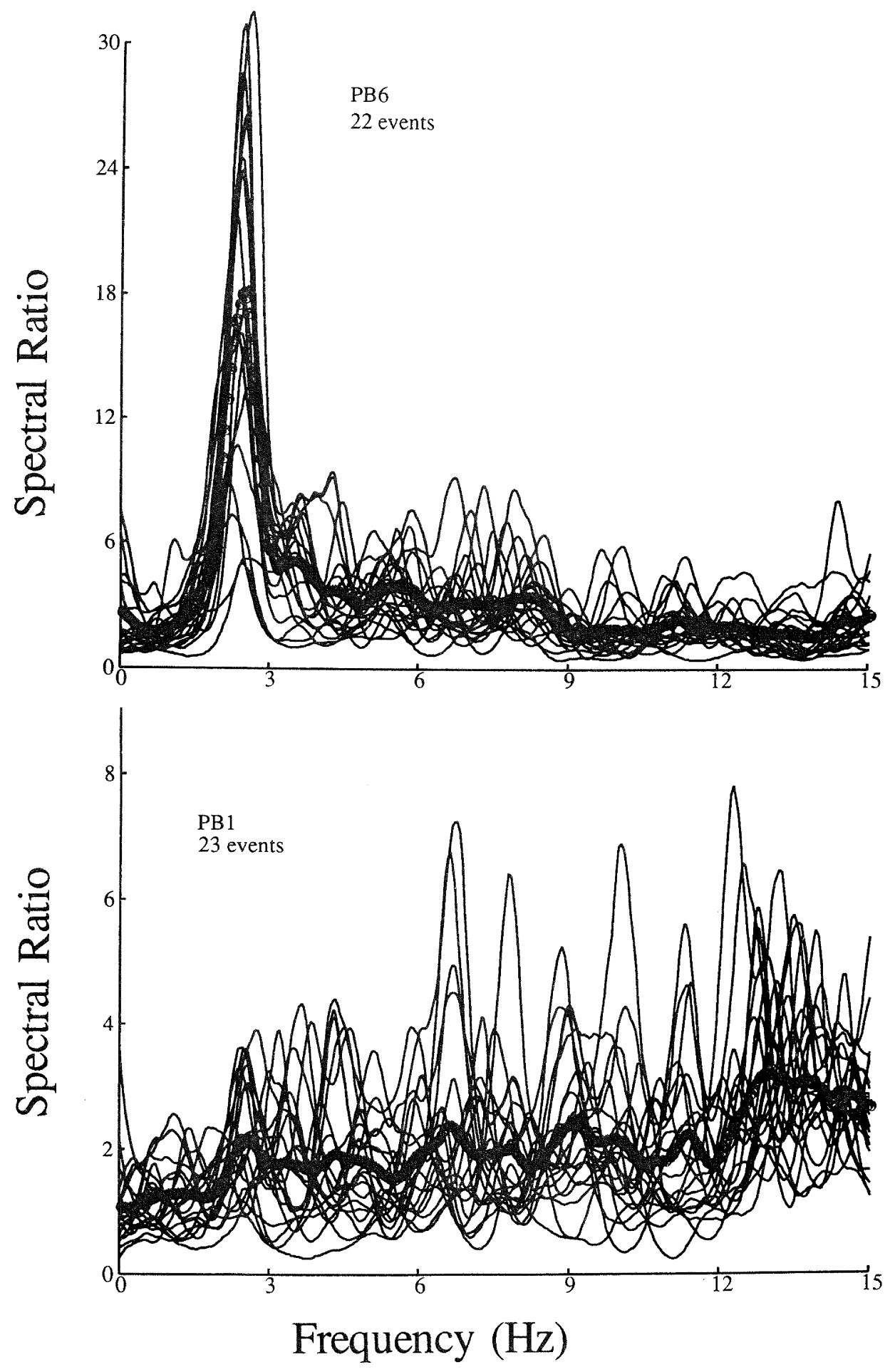

Figure A2. FSR for sites PB6 and PB1. 

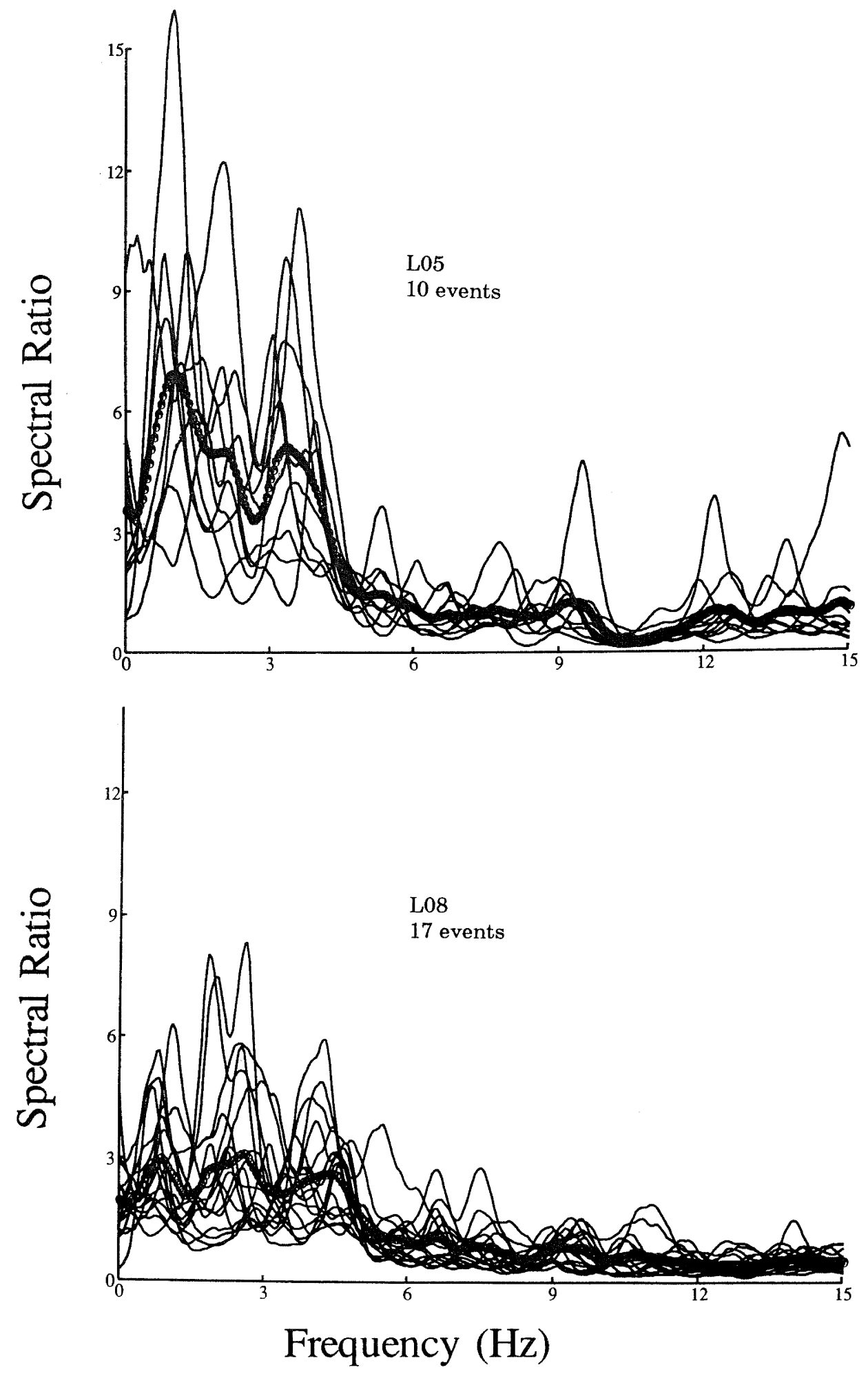

Figure A3. FSR for sites L05 and L08. 


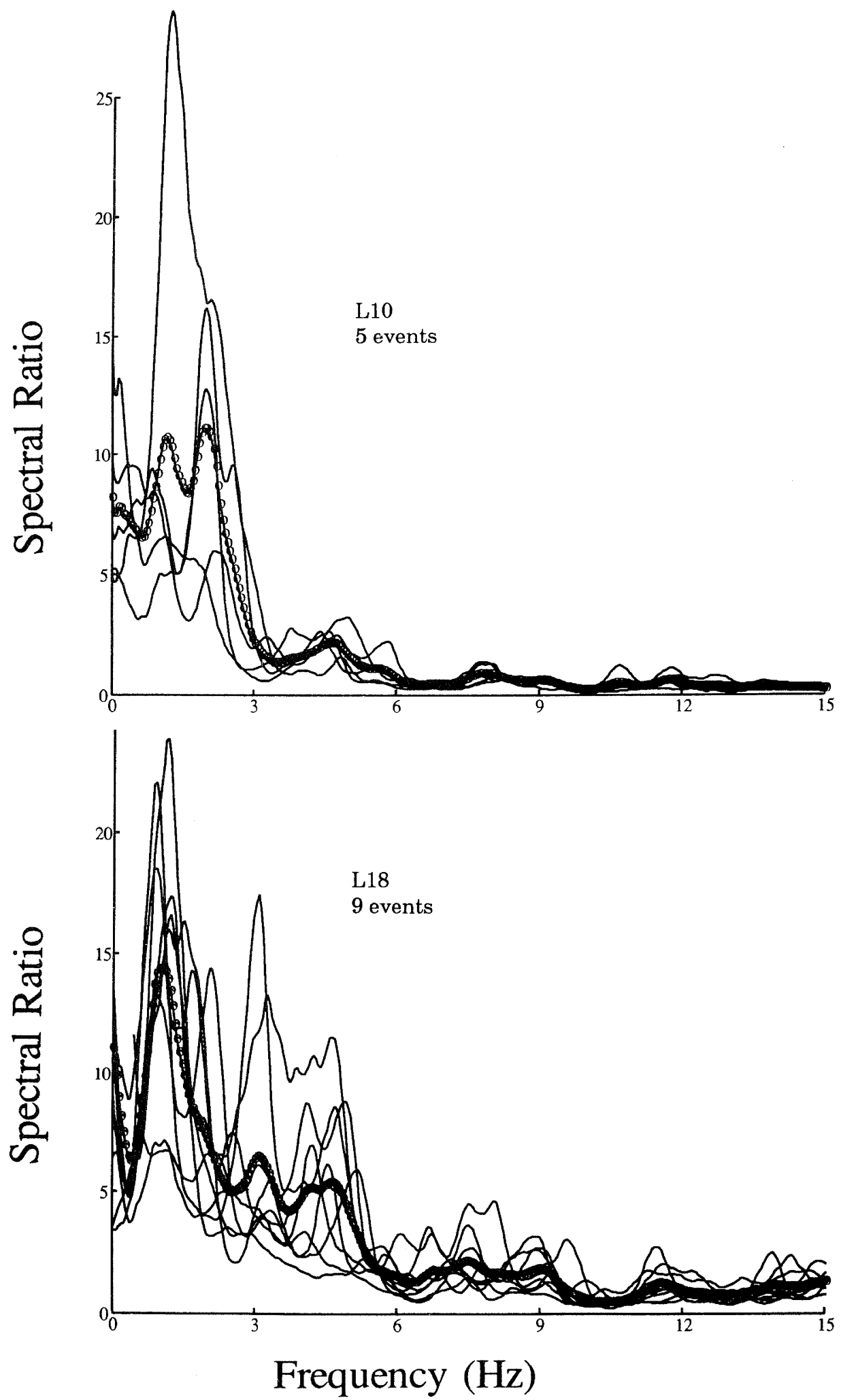

Figure A4. FSR for sites L10 and L18. 